\title{
Yanaguana Garden at Hemisfair Methods
}

Research Fellow:

Amanda Aman

Adjunct Assistant Professor

University of Texas at Arlington

Research Assistant:

Yalcin Yildirim

PhD Candidate

University of Texas at Arlington

Firm Liaison:

Amy Mitchell

MIG, Inc.

This investigation was conducted as part of the Landscape Architecture Foundation's 2019 Case Study Investigation (CSI) program. CSI matches faculty-student research teams with design practitioners to document the benefits of exemplary high-performing landscape projects. Teams develop methods to quantify environmental, economic and social benefits and produce Case Study Briefs for LAF's Landscape Performance Series.

To cite:

Aman, Amanda, and Yalcin Yildirim. "Yanaguana Garden Methods." Landscape Performance Series. Landscape Architecture Foundation, 2019. https://doi.org/10.31353/cs1571

The full case study can be found at: https://landscapeperformance.org/case-studybriefs/yanaguana-garden-at-hemisfair 


\section{Table of Contents}

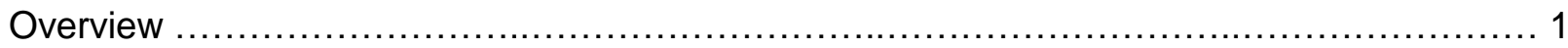

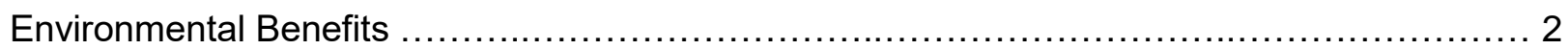

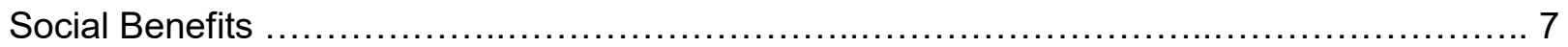

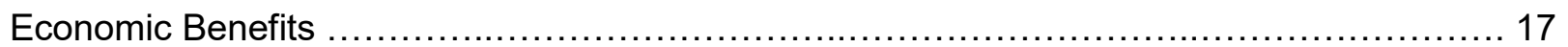

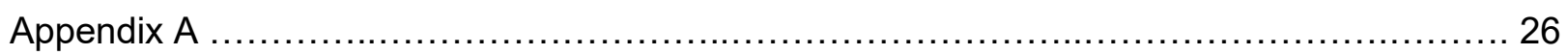

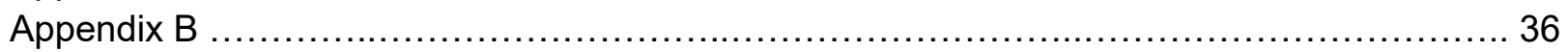

\section{Overview}

Yanaguana Garden is the first phase of implementation for the Hemisfair Area Master Plan in San Antonio, Texas. The garden replaced a 1970's-era children's play structure with a series of active and passive play spaces designed for people of all ages, abilities, and backgrounds. The garden design sought to utilize sustainable principles for conservation through the preservation of the mature tree canopy and the use of native planting and bioswales, provide a spirited environment for children and adults while highlighting play as a universal language, promote and preserve the history, culture, and art of San Antonio, provide flexibility to host a variety of programs, and support the economic development of Hemisfair.

The research outline below shows that since the garden's opening, it has helped to mitigate stormwater infiltration through permeable play surfaces and bioswales, reduced the average air temperature in the garden through the preservation of the mature tree canopy and planted surfaces, provided accessible and enjoyable play spaces for children and adults of all ages, abilities, and backgrounds, provided events, activities, and programs to preserve and educate the public on the history, culture, and art of San Antonio, and supported economic development through increases property values, visitor spending, and the establishment of new small businesses. 


\section{Environmental Benefits}

1. Captures, infiltrates, and evaporates an estimated $34 \%$ of average annual rainfall using infiltration basins and permeable play surfaces.

\section{Methods:}

A hydrological model was created for the site using the construction documents through the use of the EPA's National Stormwater Calculator (SWC) software application. The application uses input data to estimate the annual amount of rainwater and frequency of runoff for a site. Estimates are based on local soil conditions, land cover, historic rainfall records, in addition to user-supplied data for land cover and low impact development (LID) controls employed.

\section{Calculations:}

The model results from the National Stormwater Calculator analysis were used to determine the percentage of average annual rainfall captured, infiltrated, and evaporated on the site through LID controls: infiltration basins and permeable pavement. Refer to Appendix A for specific calculator steps. 


\section{Summary Results}

\section{Current Scenario}

Annual Rainfall: 33.73 in.

Runoff Infiltration Evaporation

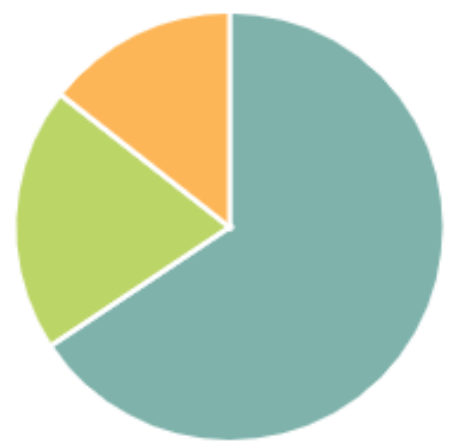

Statistic

Average Annual Rainfall (inches)

Average Annual Runoff (inches)

Days per Year with Rainfall

Days per Year with Runoff

Percent of Wet Days Retained

Smallest Rainfall w/ Runoff (inches)

Largest Rainfall w/o Runoff (inches)

Max Rainfall Retained (inches)

\section{Current Scenario}

33.73

22.37

38.87

27.43

29.43

0.20

0.40

1.05

Figure 1: Model Results Used for Calculations (National Stormwater Calculator). Refer to Appendix A for specific calculator steps.

Annual Rainfall: 33.73 in

Runoff: 22.37 in

$(22.37 \mathrm{in} / 33.73 \mathrm{in}) * 100=66.32 \%$

Infiltration \& Evaporation:

33.73 in -22.37 in $=11.36$ in

$11.36 \mathrm{in} / 33.73$ in $^{*} 100=\mathbf{3 3 . 6 8} \%$ 


\section{Sources:}

"National Stormwater Calculator." EPA. Accessed May 16, 2019.

https://swcweb.epa.gov/stormwatercalculator/

Construction document data provided by the landscape architect (MIG, Inc.) and the civil engineer (HDR, Inc).

\section{Limitations:}

The National Stormwater Calculator does not take into account tree canopy interception of rainfall for the site.

The Low Impact Development strategies calculated in this analysis (infiltration basins and permeable pavement) were based on information provided by the landscape architect and civil engineer. These areas account for a very small percentage of the site. These calculations do not account for changes in the field during construction or ongoing maintenance, replacement, or repair. Additionally, this analysis was not field verified.

The SWC tool uses rainfall data (available through the National Weather Service) from the year 2006, which is not the most recent data available for the site. Ideally, more recent data could be entered into the SWC to more accurately calculate stormwater benefits.

\section{Keeps air temperatures on a typical June day an average of $7^{\circ} \mathrm{F}$ cooler in the morning and $12^{\circ} \mathrm{F}$ cooler in the afternoon than air temperatures in an adjacent park without mature trees.}

\section{Methods:}

To determine the cooling effect of the tree canopy, the air temperature of the site was compared to the air temperature of an adjacent park with similar hardscape surface materials but with no tree canopy or vegetative cover. An ambient thermometer with 3 data loggers (with an accuracy of $\pm 1^{\circ} \mathrm{F}$ ) was used to take readings approximately 12-15 inches above the ground. Multiple locations across the site were assessed and averaged. All temperature readings were taken for both sites during the same time period on the same summer day. Additionally, the effects of water features being present on the site were assessed.

This method allowed for the comparison of temperature differences between two sites factoring in canopy coverage and the presence of vegetation. Using the data loggers, temperatures were measured in the morning (10 am) and afternoon (4 pm) for both sites on a summer weekday (Friday) and a summer weekend day (Saturday). 


\section{Calculations:}

The adjacent park site used for comparison was located at 300 South Alamo, as shown in the map below. It was selected because it was the nearest comparable park site without tree cover within 300 feet, due to limitations of the data loggers.

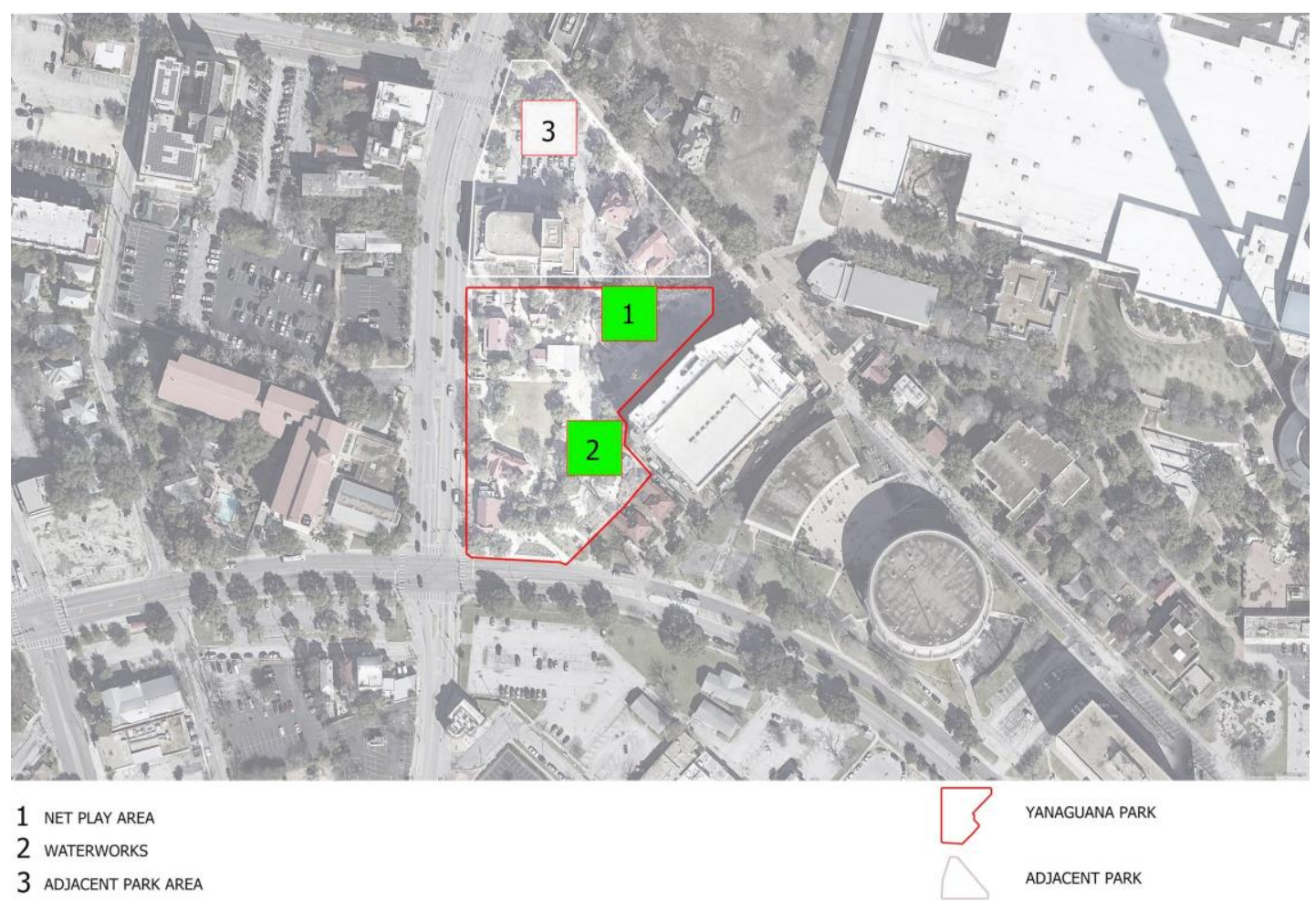

Figure 2: Temperature Collection Locations

\begin{tabular}{|c|c|c|c|c|c|c|}
\hline Location & Time & Day & Adj. Park & Park & Water & Difference $\left({ }^{\circ} \mathrm{F}\right)$ \\
\hline Net Play Area (North) & 10:00 AM & Weekday & 89.3 & 83.1 & $x$ & 6.2 \\
\hline Net Play Area (North) & 4:00 PM & Weekday & 103.5 & 90.4 & $x$ & 13.1 \\
\hline Net Play Area (North) & 10:00 AM & Weekend & 83.6 & 76.2 & $x$ & 7.4 \\
\hline Net Play Area (North) & 4:00 PM & Weekend & 101.2 & 91.3 & $x$ & 9.9 \\
\hline Water Feature Area (South) & 10:00 AM & Weekday & 94.2 & 85.7 & 91.5 & 8.5 \\
\hline Water Feature Area (South) & 4:00 PM & Weekday & 102.3 & 92.6 & 96.2 & 9.7 \\
\hline Water Feature Area (South) & 10:00 AM & Weekend & 83.4 & 76.5 & 80.2 & 6.9 \\
\hline Water Feature Area (South) & 4:00 PM & Weekend & 98.9 & 85.1 & 94.3 & 13.8 \\
\hline
\end{tabular}

Figure 3: Temperature Collection Data

The average temperature difference for both sites in the morning $(10 \mathrm{am})$ was $7.25^{\circ} \mathrm{F}$, with Yanaguana Garden consistently having lower ambient temperatures. The average temperature difference for both sites in the afternoon $(4 \mathrm{pm})$ was $11.63^{\circ} \mathrm{F}$.

$10 \mathrm{am}:(6.2+7.4+8.5+6.9) / 4=7.25$ 
4 pm: $(13.1+9.9+9.7+13.8) / 4=\mathbf{1 1 . 6 3}$

The effect of water being present on either site was inconclusive.

\section{Sources:}

This data was collected on site by the CSI research team on June 21, 2019 and June 22, 2019.

\section{Limitations:}

A more clear comparison of the vegetation's cooling effects beyond just the provision of shade would have been to compare shade conditions at Yanaguana to shade conditions at the South Alamo site; however, this was not possible due to time and equipment limitations.

The afternoon of the second day of data collection was a bit cooler due to increased cloud cover. This likely contributed to a more narrow average in temperature differences as opposed to an afternoon without cloud cover. Also, the research team relied on the ambient thermometer and data loggers for data collection. Though this equipment was tested for accuracy, there still exists the potential for slight error and inaccuracy. The range for these data loggers was 300 feet, therefore the adjacent park site had to be within that range for this comparison. 


\section{Social Benefits}

1. Supports increased visitorship to Hemisfair, with a $13 \%$ increase from the first to second year of operation (2016-2017) and a $44 \%$ increase from the second to third (2017-2018). Hemisfair hosted 1,079 events from 2015-2018 with over 600 additional events anticipated by the end of 2019.

\section{Methods:}

Attendance tracked by the client was used to determine the percentage increase in visitation at Hemisfair from 2016 to 2018.

Events were tracked by the client from 2015 to 2018.

\section{Calculations:}

Visitors

2016: 477,000 visitors

2017: 538,000 visitors

2018: 772,000 visitors

$538,000-477,000=61,000$

$(61,000 / 477,000)^{*} 100=12.79 \%$

$772,000-538,000=234,000$

$(234,000 / 538,000)^{*} 100=43.49 \%$

\section{Events}

2015 - 2016: 129

2016 - 2017: 438

2017 - 2018: 512

2018 - 2019: >600 anticipated

\section{Sources:}

Attendance and event data was provided by the client, Hemisfair and the Hemisfair Area Redevelopment Corporation (HPARC).

"Events." Hemisfair. Accessed May 19, 2019. https://hemisfair.org/events/.

\section{Limitations:}

This data was not collected by the research team. Attendance data may be considered an estimate. This data also does not distinguish repeat visits by the same visitors. 
The attendance data provided by the client was for the entirety of Hemisfair (19.2 acres) of which Yanaguana Garden is a part (3 acres). Therefore attendance numbers do not specifically pertain to the garden; however, there is a high likelihood that visitors of Hemisfair visit or pass through the garden given the adjacent restaurants and small businesses by the garden.

2. Encourages interaction between previously unacquainted visitors. At least $28 \%$ of 368 visitors were observed making new connections with other visitors on two June days.

\section{Encourages physical activity, with $69 \%$ of 368 visitors on two June days observed as being very active $(48 \%)$ or walking $(21 \%)$.}

\section{Methods:}

The System for Observing Play and Leisure Activity in Youth (SOPLAY) was utilized by the research team. SOPLAY is a validated tool for directly observing physical activity and associated environmental characteristics in free play settings. SOPLAY provides objective data on the number of participants and their physical activity levels during play and leisure opportunities in targeted areas. The research team customized this method of observation and included categories for gender, age group, ethnicity, and activity level. Participants were also observed relative to their familiarity with one another and for their types of interactions to determine whether or not new interactions were occurring during play. Familiarity was assessed through the observation of introductions by parents (observed primarily in the Play Square) or by friends (observed primarily in the Sand Play and Waterworks area), and also through the observation of rules, techniques, or modes of play being exchanged.

Four observation sessions were conducted during a weekday and weekend day in the morning (from 10 am to noon) and afternoon (6pm - 8pm). For the morning observations, the temperature was approximately $82^{\circ} \mathrm{F}$ with the humidity ranging from $58 \%-64 \%$. For the afternoon observations, the temperature was approximately $90^{\circ} \mathrm{F}$ with the humidity at approximately $70 \%$.

The highest number of participants were observed during a weekend afternoon ( $\mathrm{N}=99)$ whereas the lowest number was during a weekday afternoon $(\mathrm{N}=85)$. Observation was conducted in 7 rooms/areas of Yanaguana Garden (as listed below) and each room was observed for 15 minutes within each morning and afternoon timeframe.

\section{Calculations:}

The following data was collected on site.

Observed Age Group: $\mathrm{C}=$ Children, $\mathrm{T}=$ Teenager, $\mathrm{A}=$ Adult, $\mathrm{O}=$ Older

Observed Ethnicity: $L=$ Latino, $B=$ Black/African American, $W=$ White, $\mathrm{O}=$ Other Activity Level: $\mathrm{S}=$ Sedentary, $\mathrm{W}=$ Walking, $\mathrm{V}=$ Very Active 


\begin{tabular}{|c|c|c|c|c|c|c|c|c|c|c|c|c|c|}
\hline \multicolumn{14}{|c|}{ Weekday AM Observation } \\
\hline \multirow[t]{2}{*}{ Target Area } & \multirow[t]{2}{*}{ Participants } & \multirow{2}{*}{$\begin{array}{c}\text { \# of } \\
\text { Participants }\end{array}$} & \multicolumn{4}{|c|}{ Age Group } & \multicolumn{4}{|c|}{ Ethnicity } & \multicolumn{3}{|c|}{ Activity Level } \\
\hline & & & C & $\mathbf{T}$ & A & 0 & $\mathbf{L}$ & B & w & 0 & $\mathbf{S}$ & W & V \\
\hline \multirow{2}{*}{ Net Play Area } & Female & 7 & $\mathrm{x}$ & & & & 1 & 2 & 2 & 2 & 1 & - & 6 \\
\hline & Male & 6 & $x$ & & & & 1 & 2 & 3 & - & - & - & 6 \\
\hline \multirow{2}{*}{ Play Village } & Female & 8 & $\mathrm{x}$ & $\mathrm{x}$ & & & 3 & 1 & 4 & - & 4 & 2 & 2 \\
\hline & Male & 4 & $x$ & & & & 1 & 1 & 1 & 1 & 2 & 1 & 1 \\
\hline \multirow{2}{*}{ Play Square } & Female & 14 & $x$ & $\mathrm{x}$ & & $x$ & 5 & - & 7 & 2 & 3 & 10 & 1 \\
\hline & Male & 3 & $x$ & & & $x$ & 1 & - & 2 & - & 1 & 2 & - \\
\hline \multirow{2}{*}{ Waterworks } & Female & 17 & $x$ & & $x$ & $x$ & 5 & - & 12 & - & 3 & 2 & 12 \\
\hline & Male & 9 & $x$ & & & & 3 & - & 6 & - & 3 & 1 & 5 \\
\hline \multirow{2}{*}{$\begin{array}{l}\text { Teen gathering/ } \\
\text { community garden }\end{array}$} & Female & 4 & $x$ & & $x$ & & 2 & - & 2 & - & 2 & 2 & - \\
\hline & Male & 3 & $x$ & & $x$ & & 1 & 1 & 1 & - & 2 & 1 & - \\
\hline \multirow{2}{*}{ Play Lawn } & Female & 2 & $x$ & & $x$ & & 1 & - & 1 & & 2 & - & - \\
\hline & Male & 2 & $x$ & & $\mathrm{X}$ & & 1 & - & 1 & - & - & - & 2 \\
\hline \multirow{2}{*}{ Sand Play } & Female & 6 & $x$ & $X$ & & & 2 & - & 4 & - & - & - & 6 \\
\hline & Male & 10 & $x$ & $\mathrm{X}$ & & & 3 & 3 & 4 & - & 1 & - & 9 \\
\hline
\end{tabular}

\begin{tabular}{|c|c|c|c|c|c|c|c|c|c|c|c|c|c|}
\hline \multicolumn{14}{|c|}{ Weekday PM Observation } \\
\hline \multirow[t]{2}{*}{ Target Area } & \multirow[t]{2}{*}{ Participants } & \multirow[t]{2}{*}{$\begin{array}{c}\text { \# of } \\
\text { Participant }\end{array}$} & \multicolumn{4}{|c|}{ Age Group } & \multicolumn{4}{|c|}{ Ethnicity } & \multicolumn{3}{|c|}{ Activity Level } \\
\hline & & & C & $\mathbf{T}$ & A & 0 & $\mathbf{L}$ & B & w & 0 & $\mathbf{S}$ & w & V \\
\hline \multirow{2}{*}{ Net Play Area } & Female & 6 & $x$ & & & & 4 & - & 1 & 1 & 2 & - & 4 \\
\hline & Male & 5 & $x$ & & & & 3 & 1 & 1 & - & - & - & 5 \\
\hline \multirow{2}{*}{ Play Village } & Female & 9 & $x$ & $x$ & & & 5 & 1 & 3 & - & 4 & 2 & 3 \\
\hline & Male & 5 & $x$ & & & & 3 & 1 & 1 & - & 1 & 1 & 3 \\
\hline \multirow{2}{*}{ Play Square } & Female & 6 & $x$ & & & & 3 & & 1 & 2 & 3 & 1 & 2 \\
\hline & Male & 5 & $x$ & & & & 4 & - & 1 & - & 1 & 2 & 2 \\
\hline \multirow{2}{*}{ Waterworks } & Female & 16 & $x$ & & $x$ & & 3 & 2 & 10 & 1 & 3 & 4 & 9 \\
\hline & Male & 7 & $x$ & & & $x$ & 2 & - & 5 & - & 3 & 1 & 3 \\
\hline \multirow{2}{*}{$\begin{array}{l}\text { Teen gathering/ } \\
\text { community garden }\end{array}$} & Female & 3 & & $x$ & & & 2 & - & 1 & - & 2 & 1 & - \\
\hline & Male & 3 & & $x$ & & & 1 & 1 & 1 & - & 1 & - & 2 \\
\hline \multirow{2}{*}{ Play Lawn } & Female & 8 & & & & & 2 & - & 6 & - & 1 & 7 & - \\
\hline & Male & 5 & & & & & 1 & - & 4 & - & 1 & 4 & - \\
\hline \multirow{2}{*}{ Sand Play } & Female & 4 & $X$ & & & & 3 & - & 1 & - & 1 & - & 3 \\
\hline & Male & 3 & $x$ & & & & 2 & - & 1 & - & - & - & 3 \\
\hline
\end{tabular}




\begin{tabular}{|c|c|c|c|c|c|c|c|c|c|c|c|c|c|}
\hline \multicolumn{14}{|c|}{ Weekend AM Observation } \\
\hline \multirow[t]{2}{*}{ Target Area } & \multirow[t]{2}{*}{ Participants } & \multirow{2}{*}{$\begin{array}{c}\text { \# of } \\
\text { Participant }\end{array}$} & \multicolumn{4}{|c|}{ Age Group } & \multicolumn{4}{|c|}{ Ethnicity } & \multicolumn{3}{|c|}{ Activity Level } \\
\hline & & & $\mathbf{C}$ & $\mathbf{T}$ & A & 0 & $\mathbf{L}$ & B & W & 0 & $\mathbf{S}$ & w & V \\
\hline \multirow{2}{*}{ Net Play Area } & Female & 4 & $\mathrm{x}$ & & & & 2 & - & 2 & - & 3 & - & 1 \\
\hline & Male & 2 & $x$ & & & & 1 & 2 & - & - & - & - & 2 \\
\hline \multirow{2}{*}{ Play Village } & Female & 6 & $\mathrm{x}$ & $\mathrm{x}$ & & & 3 & 1 & 2 & - & 4 & - & 2 \\
\hline & Male & 5 & $x$ & & & & 2 & 1 & 2 & - & 3 & - & 2 \\
\hline \multirow{2}{*}{ Play Square } & Female & 13 & $\mathrm{x}$ & $\mathrm{x}$ & & $x$ & 10 & - & 3 & - & 9 & 1 & 3 \\
\hline & Male & 4 & $x$ & & $x$ & $x$ & 3 & - & 1 & - & 2 & 1 & 1 \\
\hline \multirow{2}{*}{ Waterworks } & Female & 24 & $\mathrm{x}$ & & $\mathrm{X}$ & $x$ & 16 & 2 & 5 & 1 & 7 & 4 & 13 \\
\hline & Male & 13 & $x$ & & & & 5 & 1 & 6 & - & 3 & 2 & 8 \\
\hline \multirow{2}{*}{$\begin{array}{l}\text { Teen gathering/ } \\
\text { community garden }\end{array}$} & Female & 3 & $\mathrm{x}$ & & & $x$ & 2 & - & 1 & - & 1 & 1 & 1 \\
\hline & Male & 2 & $x$ & & & $x$ & 1 & - & 1 & - & 1 & 1 & - \\
\hline \multirow{2}{*}{ Play Lawn } & Female & 4 & $\mathrm{x}$ & & $x$ & & 2 & 1 & 1 & - & 2 & 1 & 1 \\
\hline & Male & 3 & $x$ & & $x$ & & 1 & 1 & 1 & - & 1 & - & 2 \\
\hline \multirow{2}{*}{ Sand Play } & Female & 4 & $\mathrm{x}$ & $x$ & & & 1 & 1 & 2 & - & 1 & - & 3 \\
\hline & Male & 3 & $\mathrm{x}$ & $x$ & & & 1 & - & 2 & - & 1 & - & 2 \\
\hline
\end{tabular}

\begin{tabular}{|c|c|c|c|c|c|c|c|c|c|c|c|c|c|}
\hline \multicolumn{14}{|c|}{ Weekend PM Observation } \\
\hline \multirow[t]{2}{*}{ Target Area } & \multirow[t]{2}{*}{ Participants } & \multirow{2}{*}{$\begin{array}{c}\text { \# of } \\
\text { Participant }\end{array}$} & \multicolumn{4}{|c|}{ Age Group } & \multicolumn{4}{|c|}{ Ethnicity } & \multicolumn{3}{|c|}{ Activity Level } \\
\hline & & & C & $\mathbf{T}$ & A & 0 & $\mathbf{L}$ & B & W & 0 & $\mathbf{S}$ & w & V \\
\hline \multirow{2}{*}{ Net Play Area } & Female & 8 & $x$ & & & $x$ & 4 & 2 & 3 & - & 3 & 1 & 4 \\
\hline & Male & 5 & $x$ & & $x$ & & 1 & 2 & 2 & - & - & 3 & 2 \\
\hline \multirow{2}{*}{ Play Village } & Female & 7 & $x$ & $x$ & & & 4 & 1 & 2 & - & 4 & 1 & 2 \\
\hline & Male & 4 & $x$ & & & & 1 & 1 & 2 & - & 2 & - & 2 \\
\hline \multirow{2}{*}{ Play Square } & Female & 11 & $x$ & $\mathrm{X}$ & & $x$ & 6 & 2 & 3 & - & 7 & 1 & 3 \\
\hline & Male & 6 & $x$ & & $x$ & $x$ & 3 & 2 & 1 & - & 2 & 2 & 2 \\
\hline \multirow{2}{*}{ Waterworks } & Female & 20 & $x$ & & $x$ & $x$ & 13 & 3 & 4 & - & 3 & 4 & 13 \\
\hline & Male & 12 & $x$ & & & & 5 & 1 & 6 & - & 2 & 2 & 8 \\
\hline \multirow{2}{*}{$\begin{array}{l}\text { Teen gathering/ } \\
\text { community garden }\end{array}$} & Female & 5 & $x$ & & & $x$ & 2 & 2 & 1 & - & 1 & 3 & 1 \\
\hline & Male & 3 & $x$ & & & $x$ & 1 & 1 & 1 & - & 1 & 1 & 1 \\
\hline \multirow{2}{*}{ Play Lawn } & Female & 4 & $x$ & $x$ & & & 2 & 1 & 1 & - & 2 & 1 & 1 \\
\hline & Male & 4 & $x$ & & $x$ & & 2 & 1 & 1 & - & 2 & - & 2 \\
\hline \multirow{2}{*}{ Sand Play } & Female & 6 & $x$ & & $x$ & & 2 & 2 & 2 & - & 1 & 2 & 3 \\
\hline & Male & 4 & $\mathrm{X}$ & & & $x$ & 1 & 1 & 2 & - & 1 & - & 2 \\
\hline
\end{tabular}

Figure 4: SOPLAY Observation Data

\section{Observation of Physical Activity:}

The total number of visitors engaged in physical activity [categories $\mathrm{W}=$ Walking (76) and $\mathrm{V}=$ Very Active(176)] was 252.

$$
252 / 368=.685^{\star} 100=68.5 \%
$$

\section{Observation of Familiarity:}

Visitors in the Net Play Area and the Waterworks area were observed as having the highest amount of initial familiarity with one another (belonging to the same family or friend group). Visitors in the Play Square and Sand Play Area were observed as having the least amount of familiarity with one another. The total number of visitors identified as probable new acquaintances (visitors interacting that did not appear to be within the same family/friend group initially) [Play Square (62) and Sand Play (40)] was 102. These two locations were identified as being the most conductive to creating interactions between visitors who do not know one another, but visitors in the other areas also were likely to have been making some of these types of connections, hence this benefit is 
reported "at least".

$$
102 / 368=.277^{*} 100=27.7 \%
$$

As a general observation, visitor interactions within the Play Square were comprised of a mix of teenagers and elderly visitors who were often teaching others how to play the games available, including chess. The visitor interactions within the Sand Play area were comprised of children of a variety of ethnicities and ages who were often teaching each other how to build sand castles and water channels.

\section{Observation of Diversity:}

The park use among females was identified at $62 \%(\mathrm{~N}=229)$ and $38 \%$ for males $(\mathrm{N}=140)$. However, for children engaged in very active play, the pattern changed with females comprising $43 \%(\mathrm{~N}=99)$ and $55 \%$ for males $(\mathrm{N}=77)$. With regard to race/ethnicity, a majority of the park users were Latino at $44.7 \%(\mathrm{~N}=165)$, followed by White and African-American at 39.8\% ( $\mathrm{N}=147)$ and $13 \%(\mathrm{~N}=48)$, respectively. Approximately $40 \%$ of African-American park users preferred the Play Square while almost $37 \%$ of White park users and $32 \%$ of Latino park users preferred the Waterworks area.

\section{Sources:}

"Active Living Research." SOPLAY: System for Observing Play and Leisure Activity in Youth | Active Living Research. Accessed June 27, 2019.

https://activelivingresearch.org/soplay-system-observing-play-and-leisure-activity-youth.

The CSI research team performed the data collection and analysis.

\section{Limitations:}

The sample size was limited due to the number of hours the CSI research team could spend on the site. Additionally, interactions that were observed could have been inaccurately interpreted due to human error in the field, i.e. visual assessment of ethnicity, age group, interactions, etc.

\section{Methods for all survey results:}

A user survey was developed to assess the amenities and services preferred by people visiting the site and was offered in English and Spanish. The survey was administered on Friday June 21, 2019 and Saturday June 22, 2019 from 9 am to 5 pm. The research team rotated between locations of frequent circulation and occupancy and asked visitors if they would be interested in taking a survey about the site and its amenities. Complete survey results were entered into a digital Qualtrics survey platform and were analyzed. The full survey can be found in Appendix B.

\section{Sources:}

Survey Questions (refer to Appendix B) 
Survey administration was conducted by the CSI research team with additional administration provided by Hemisfair and the Hemisfair Area Redevelopment Corporation (HPARC) through social media outlets.

\section{Limitations:}

The sample size was limited due to the number of hours the CSI research team could spend on the site. The research team was aware of bias that can occur with convenience sampling. The team inquired with as many visitors as possible in order to obtain respondents for the survey. Administering the survey during one week day during work hours and one weekend day affected the cross-section of visitors captured. In order to supplement the total number of respondents obtained on site, the survey was also administered online and was sent to the general public and park employees through social media platforms and through email. This was accomplished with the help of the client, Hemisfair.

\section{Provides educational and cultural value. $65 \%$ of 82 surveyed visitors agreed that the art in the garden has helped them understand the site's cultural and historical importance.}

\section{Calculations:}

Question: Could you rate the following statements regarding your experience with Yanaguana Garden?

53 respondents highly rated "The art in the garden has helped me understand its cultural and historical importance."

$$
53 / 82=.646^{*} 100=64.6 \%
$$

82 total respondents

Personal interviews with respondents revealed that they would like to see additional signage at the historical buildings on the site to increase awareness of the park's historical significance.

\section{Sources:}

Survey Questions (refer to Appendix B)

5. Has a high or very high aesthetic quality for $95 \%$ of 82 surveyed visitors who were asked to rate the beauty or attractiveness of the garden.

\section{Calculations:}

Question: How would you rate the aesthetic quality (beauty or attractiveness) of the garden?

78 respondents highly rated the aesthetic quality of the garden 
$78 / 82=.951^{*} 100=95.1 \%$

82 total respondents

\section{Sources:}

Survey Questions (refer to Appendix B)

6. Allows visitors to access, use, and enjoy all play features according to $94 \%$ of 82 surveyed visitors. Through interviews, 3 visitors who identified as having a disability reported that they felt the site was accessible.

\section{Calculations:}

Question: Are you able to access/use/enjoy all play features?

77 respondents answered "Yes"

$$
77 / 82=.939 * 100=93.9 \%
$$

5 respondents answered "No"

82 total respondents

Question: Do you have a disability or condition that may affect your ability to utilize the play and garden features?

3 respondents answered "Yes"

$$
3 / 82=.037^{\star} 100=3.7 \%
$$

79 respondents answered "No"

82 total respondents

Follow-up personal interviews with the 3 respondents identifying as having a disability revealed that they felt the site was accessible. They also communicated their desire for swings that were inclusive to visitors that use a wheelchair in addition to sensory-friendly elements.

\section{Sources:}

Survey Questions (refer to Appendix B)

7. Provides improved park access for over 2,000 households within a half-mile. Over one-third of these 3,630 residents are low-income.

\section{Methods:}

Using a combination of ACS data and ESRI ArcGIS software, a 1/2-mile buffer zone around the garden was defined. The smallest scale of geographic units was determined for the census block groups in order to analyze the population data within the buffer zone. Components of the population data were then extracted including residents living within the buffer zone neighborhoods in addition to those who are considered low income. 


\section{Calculations:}

A combination of ACS data and ESRI ArcGIS software was used to extract population data.

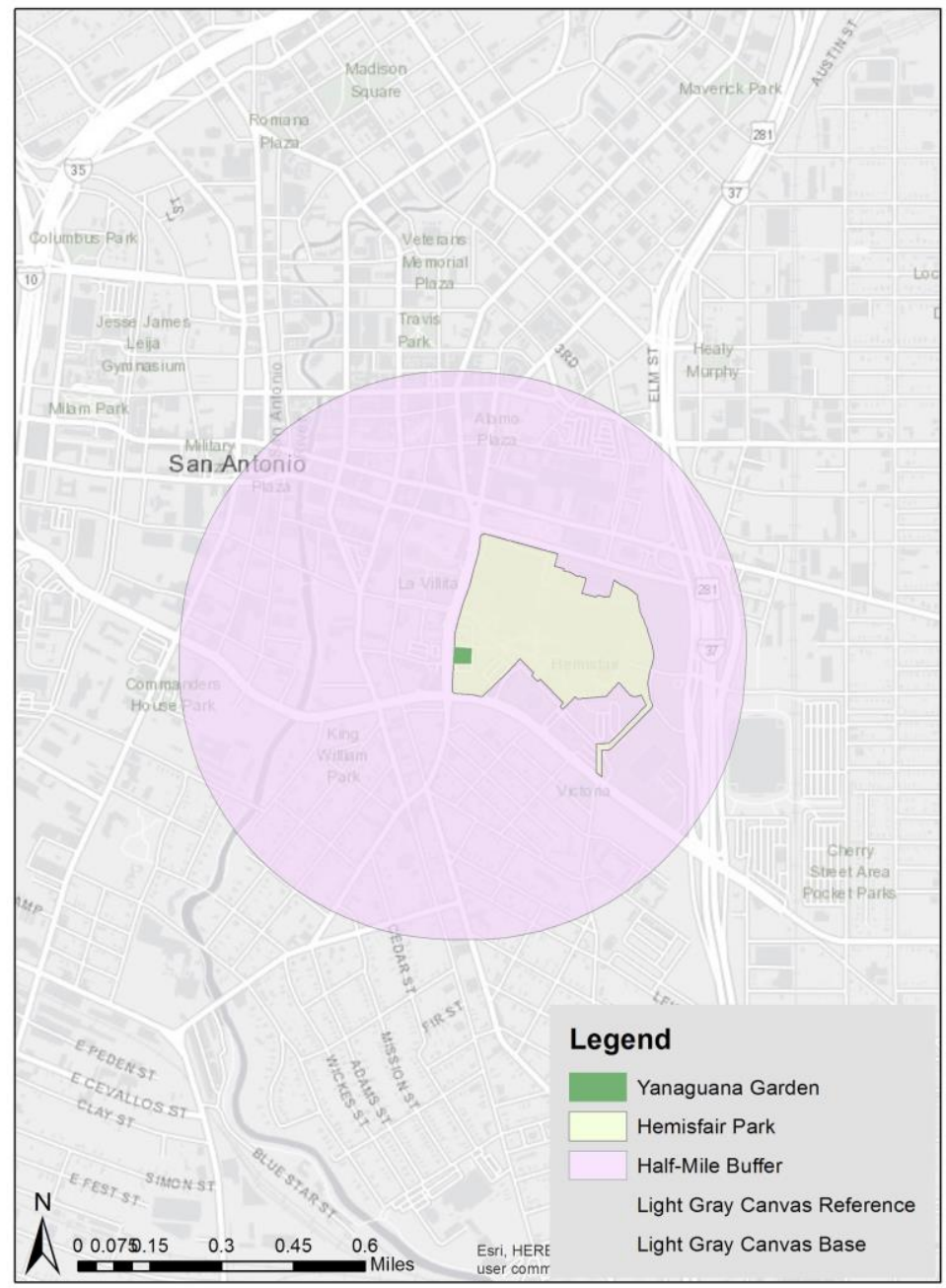

Figure 5: Yanaguana Garden 1/2 Mile Buffer Zone (ESRI ArcGIS)

\section{Sources:}

American Community Survey. 2017.

City of San Antonio Spatial Data for parks data. Retrieved May 11, 2019 from http://opendata-cosagis.opendata.arcgis.com/

ESRI ArcGIS Tools for mapping and figures

\section{Limitations:}

The software collates and cross-references many types of spatial datasets by location and is continuously updated. However, the software can sometimes inherit errors or inaccuracies every time a new dataset is imported which can skew results. Additionally, 
barriers to park access (heavily trafficked streets, lack of crosswalks or pedestrian zones, etc.) are not accounted for in this analysis. While our use of a $1 / 2-$ mile radius is a proxy for proximity to the park, this does not necessarily mean that the park is equally accessible.

8. Contributes to an increase in social media engagement for Hemisfair as demonstrated by a $34 \%$ increase in social media followers, an $80 \%$ increase in social media interactions, and a $48 \%$ increase in direct messages sent and received from 2018 to 2019.

\section{Methods:}

Social media is a widely-used communication tool and contributes to the success of a project through engagement with followers and the exchange of information. Social media data was tracked by the client on social media platforms including Twitter, Facebook, and Instagram.

\section{Calculations:}

Data provided by the client.

\section{Sources:}

Social media data was provided by the client, Hemisfair and the Hemisfair Area Redevelopment Corporation (HPARC).

\section{Limitations:}

This data was not collected by the CSI research team and methods of collection and calculation cannot be verified.

The social media data provided by the client was for the entirety of Hemisfair for which Yanaguana Garden is a part of. Therefore, social media activity does not specifically pertain to the garden. Yanaguana Garden, as a high-use new area of Hemisfair, can be assumed to contribute to this increased engagement.

\section{Economic Benefits}

1. Contributed to a $\mathbf{5 0 \%}$ average increase in assessed property value for $\mathbf{7 4}$ randomly selected parcels within a two-block radius from 2015 to 2019.

\section{Methods:}

Analysis was performed 74 randomly selected units/parcels within a two-block radius in order to understand the impact the park has made on neighboring property values. Unit and parcel data for property values within a specified period of time (2015-2019) was 
obtained from the Bexar County Appraisal District (BCAD) interactive map tool. Before finalizing the selection of units/parcels, data that was not accurately extracted or still pending was removed. The percentage increase in property value for each unit/parcel was calculated, upper and lower outliers were removed, and then the average for these units/parcels was used as a final estimate for the increase in property values from 2015 (before the park was constructed) to 2019 (current).

\section{Calculations:}

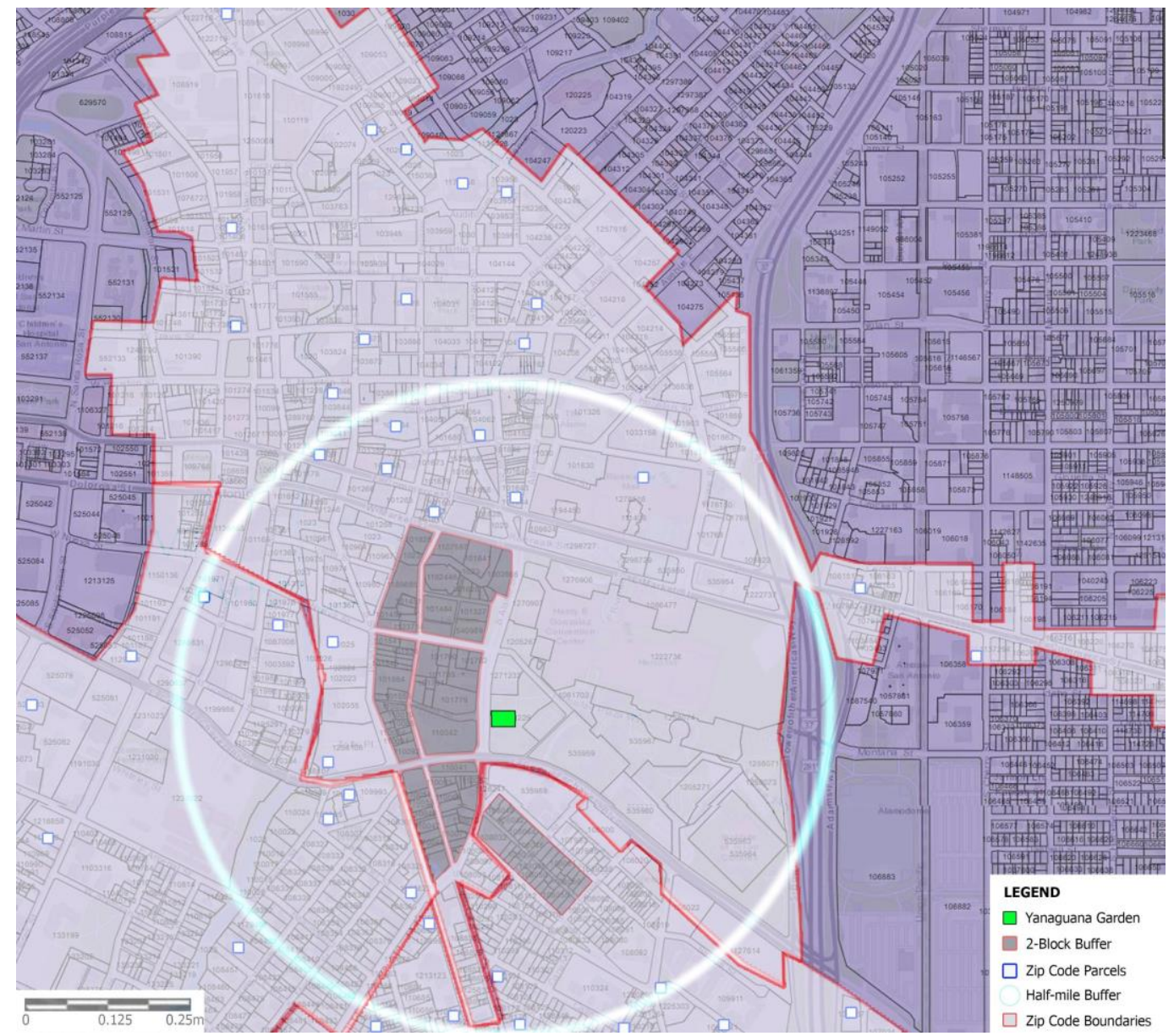

Figure 6: Yanaguana Garden Selected Units/Parcels Map (ESRI ArcGIS)

Two geographic scales were used to analyze property values: half-mile radius and twoblock radius of Yanaguana Garden. The property values for the selected units/parcels were extracted from the Bexar County Appraisal District between 2015 and 2019. The change in property values for each unit/parcel was converted to a percentage and listed in the table below. These percentages were then averaged to obtain the average increase in property value.

The available data for the last 5 years was defined first. This time frame was important as the team wanted to assess the data from the two years prior to the garden's opening through two years after the garden's opening (the garden opening was in 2017, therefore 
the range of 2015-2019 was used). The properties that did not have data during this time frame were excluded from the data. After this elimination, the team used the Bexar County Tax Mapping for random selection in order to select diverse business/property categories. The majority of the businesses/properties within these parcels were either related to hospitality or parking, so in order to diversify the data to include more than just these two categories, the team included additional business types including car rental facilities, restaurants, real estate development offices, law offices, educational facilities, etc. Therefore, the values between 2015 and 2019 comprised the data to provide a comprehensive and standard comparison among parcels.

Example unit/parcel data:

\begin{tabular}{|c|c|c|c|c|c|c|c|c|}
\hline Property ID & Geo ID & Address & Doing Business & Year & $\begin{array}{c}\text { Assessed } \\
\text { Value }\end{array}$ & Increase (2019-2015) & Ratio & $\%$ \\
\hline \multirow{5}{*}{101644} & \multirow{5}{*}{$\begin{array}{c}00145-000- \\
0130\end{array}$} & \multirow{5}{*}{$\begin{array}{c}101 \text { ALAMO } \\
\text { PLZSAN } \\
\text { ANTONIO, TX } \\
78205\end{array}$} & \multirow{5}{*}{ DULLNIG BLDG/ RIVERWALK VISTA HOTEL 17 ROOMS } & 2019 & $\$ 3,192,350$ & \multirow{5}{*}{$792,350.00$} & \multirow{5}{*}{0.33014583} & \multirow{5}{*}{$33.01 \%$} \\
\hline & & & & 2018 & $\$ 3,100,000$ & & & \\
\hline & & & & 2017 & $\$ 3,000,000$ & & & \\
\hline & & & & 2016 & $\$ 2,700,000$ & & & \\
\hline & & & & 2015 & $\$ 2,400,000$ & & & \\
\hline
\end{tabular}


HALF MILE BUFFER

\begin{tabular}{|r|}
\hline $40.35 \%$ \\
\hline $41.67 \%$ \\
\hline
\end{tabular}

$44.38 \%$

$41.33 \%$

$43.22 \%$

$43.22 \%$

$44.37 \%$

$43.64 \%$

$43.22 \%$

$44.38 \%$

$34.52 \%$

$74.58 \%$

$33.20 \%$

$34.74 \%$

$109.72 \%$

$107.80 \%$

$114.21 \%$

$120.06 \%$

$46.40 \%$

$29.67 \%$

$19.93 \%$

$18.56 \%$

$26.32 \%$

$62.65 \%$

$86.27 \%$

$29.41 \%$

$13.89 \%$

$29.38 \%$

$113.57 \%$

$184.06 \%$

$21.71 \%$

$43.71 \%$

$49.85 \%$

$39.47 \%$

$44.19 \%$

$70.32 \%$

$44.03 \%$

$112.07 \%$

$44.36 \%$

$-10.40 \%$

$71.68 \%$

$44.37 \%$

$43.64 \%$

$43.64 \%$

$43.64 \%$

$43.64 \%$

$43.65 \%$

$67.08 \%$

$43.63 \%$

$43.64 \%$

$194.37 \%$

$44.28 \%$

$44.32 \%$

$44.38 \%$

$44.38 \%$

$44.38 \%$

$34.67 \%$

$31.04 \%$

$76.22 \%$

$76.22 \%$

$20.62 \%$

$76.22 \%$

$76.22 \%$

$55.07 \%$

$50.21 \%$

Figure 7: Yanaguana Garden Selected Units/Parcels Data (Bexar County Appraisal District) 


\section{Sources:}

Bexar County Property Search. Accessed May May 27, 2019

http://www.bcad.org/clientdb/propertysearch.aspx?cid=1

ESRI ArcGIS Tools for mapping and figures.

\section{Limitations:}

County-level appraisal data was used for these calculations, therefore the accuracy of the data is dependent on the property value sources which the CSI research team did not independently verify.

As a note, the unit/parcel locations were obtained from Google Maps and Google Earth and were enlarged in the maps for illustrative purposes.

Additionally, other factors outside of the park can contribute to these increases.

\section{Catalyzes visitor spending, with $82 \%$ of 82 surveyed visitors reporting patronizing businesses and restaurants within a 2-block radius of Yanaguana Garden.}

\section{Methods:}

A user survey was developed to assess the amenities and services preferred by people visiting the site and was offered in English and Spanish. The survey was administered on Friday June 21, 2019 and Saturday June 22, 2019 from 9 am to 5 pm. The research team rotated between locations of frequent circulation and occupancy and asked visitors if they would be interested in taking a survey about the site and its amenities. Complete survey results were entered into a digital Qualtrics survey platform and were analyzed. The full survey can be found in Appendix B.

\section{Calculations:}

Question: Have you visited any nearby businesses/restaurants as part of your visit to the garden? If so, which ones?

67 respondents answered "Yes"

$$
67 / 82=.817^{*} 100=81.7 \%
$$

15 respondents answered "No"

82 total respondents

The most visited nearby businesses/restaurants according to respondents include:

Paleteria: $27 / 82=.329 * 100=32.9 \%$

Dough Pizzeria: $26 / 82=.317^{*} 100=31.7 \%$

CommonWealth Coffee House: $18 / 82=.220 * 100=22.0 \%$

Con Safos-Cocina Y Cantina: $16 / 82=.195^{\star} 100=19.5 \%$

Chocollazo: $8 / 82=.098 * 100=\mathbf{9 . 8} \%$

Silo: $8 / 82=.098^{\star} 100=9.8 \%$ 
Battalion: $7 / 82=.085^{*} 100=8.5 \%$

\section{Sources:}

Survey Questions (refer to Appendix B)

\section{Limitations:}

The sample size was limited due to the number of hours the CSI research team could spend on the site. The research team was aware of bias that can occur with

convenience sampling. The team inquired with as many visitors as possible in order to obtain respondents for the survey. Administering the survey during one week day during work hours and one weekend day affected the cross-section of visitors captured. In order to supplement the total number of respondents obtained on site, the survey was also administered online and was sent to the general public and park employees through social media platforms and through email. This was accomplished with the help of the client, Hemisfair.

\section{Contributed to a $\mathbf{1 8 2} \%$ increase in the median property tax revenue for owner-} occupied homes in the surrounding census tracts from 2013 to 2017, compared to an $8 \%$ increase for Bexar County as a whole.

\section{Methods:}

The U.S. Census Bureau American Fact Finder was used to access census and American Community Survey data before (2013) and after the construction of the garden (2017). The American Community Survey produces population, demographic, and housing unit estimates as well as property tax revenue data for owner-occupied homes. For comparison, the census tract adjacent to/surrounding the garden was analyzed and compared to Bexar County median data.

\section{Calculations:}

Property Taxes Census Tract 1109:

Median dollars (2017): 3,119

Median dollars (2013): 1,107

Amount of Change: $+2,012$

Percent Change: $\mathbf{1 8 1 . 7 5 \%}$

Property Taxes in Bexar County:

Median dollars (2017): 2,828

Median dollars (2013): 2,623

Amount of Change: +205

Percent Change: $\mathbf{7 . 8 2 \%}$ 


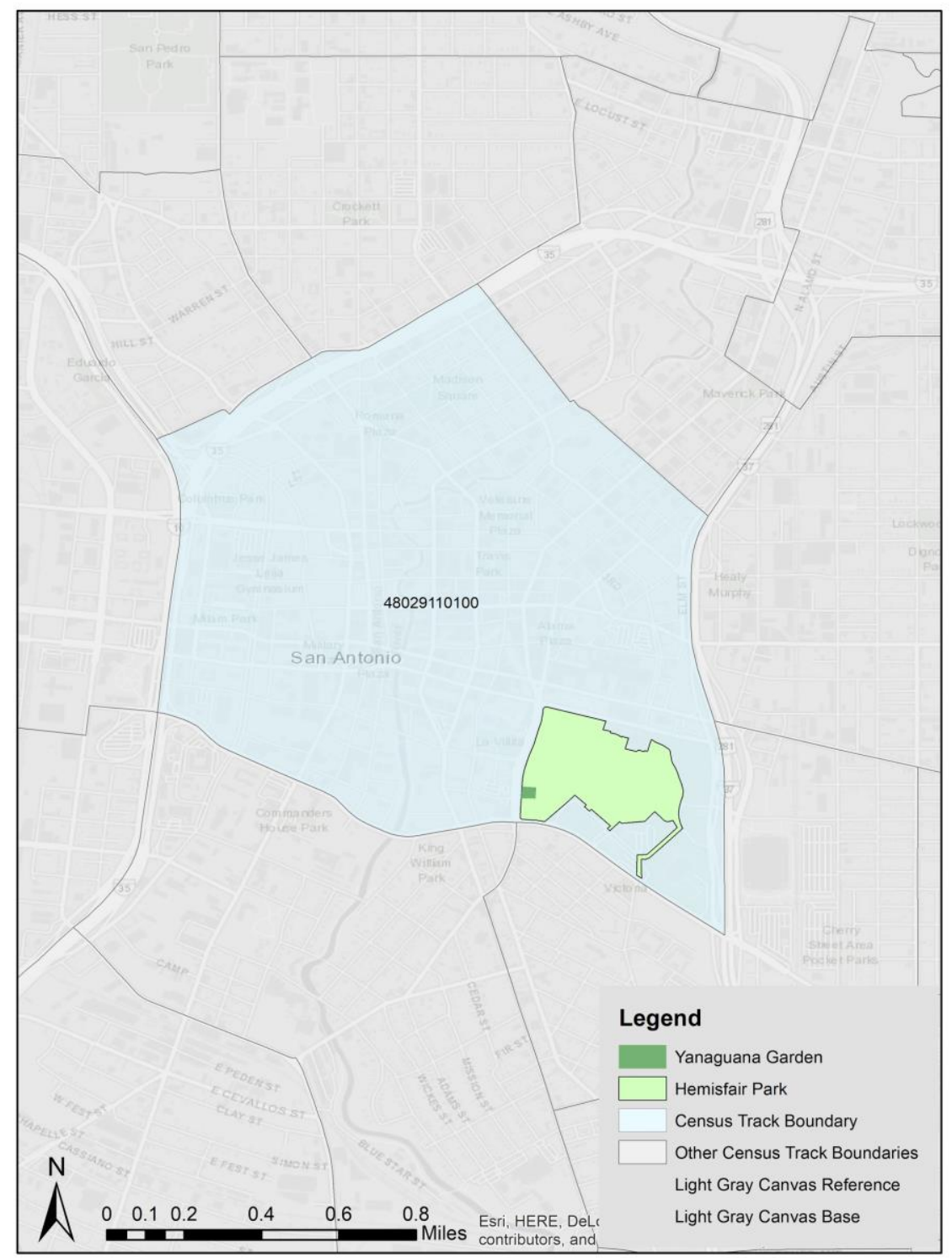

Figure 8: Census Tract (ESRI ArcGIS) 


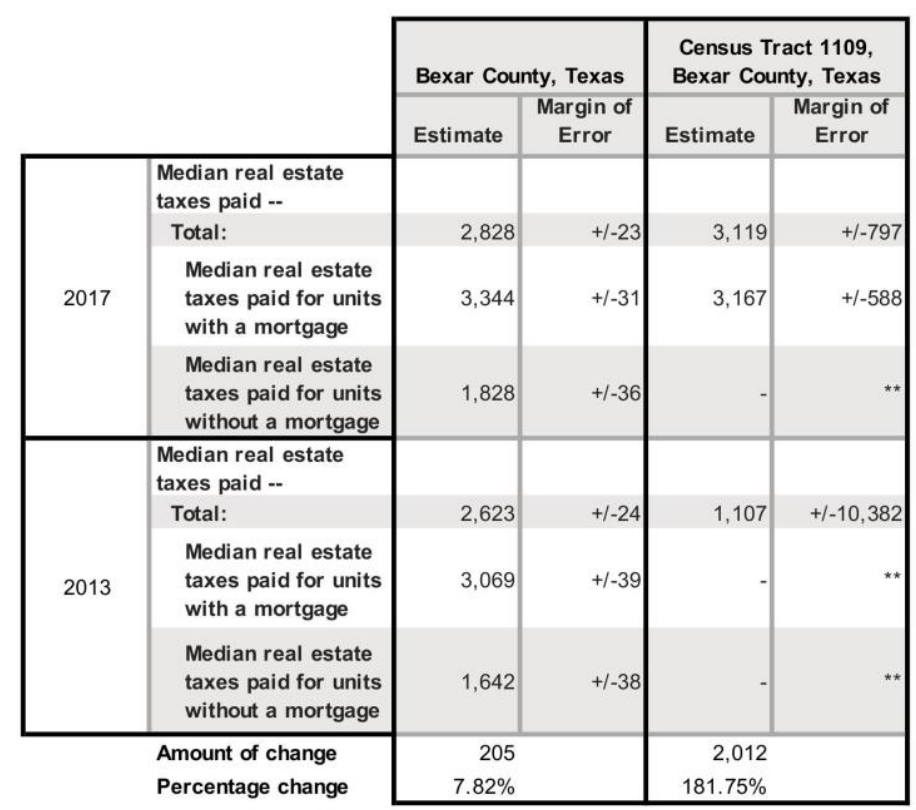

Figure 9: Calculations for Median Property Tax Revenue (United States Census Bureau)

\section{Sources:}

American Community Survey. United States Census Bureau - American Fact Finder. Accessed May 19th, 2018. https://factfinder.census.gov

\section{ESRI ArcGIS Mapping Tools}

United States Census Bureau - American Fact Finder. Accessed May 19, 2018.https://factfinder.census.gov

\section{Limitations:}

2017 was the most recent data available for median property tax revenue in the area.

Additionally, other factors outside of the park can contribute to these increases.

\section{Helped to catalyze the establishment of at least 4 new businesses within a 3-block radius and 6 small and minority-owned businesses on-site.}

\section{Methods:}

The client (the Hemisfair Redevelopment Corporation) aided in the establishment of new small and minority-owned business opportunities on-site (through marketing and support for permitting) and provided this data. Additionally, the client provided data on new businesses that have opened within a 3 block radius since the opening of Yanaguana Garden.

\section{Calculations:}


New businesses opened within a 3-block radius since the opening of Yanaguana Garden:

Noona

Silo

Battallion

Maverick

New small and minority-owned businesses opportunities launched on-site (with the help of Hemisfair) since the opening of Yanaguana Garden.

Paleteria

Con Safos-Cocina y Cantina

CommonWealth Coffee House

Dough Pizzeria

Blue Cat Yoga

Chocollazo

\section{Sources:}

Small business data was provided by the client, Hemisfair and the Hemisfair Area Redevelopment Corporation (HPARC).

\section{Limitations:}

This data was not collected by the CSI research team. 


\section{Appendix A}

\section{\&EPA National Stormwater Calculator}

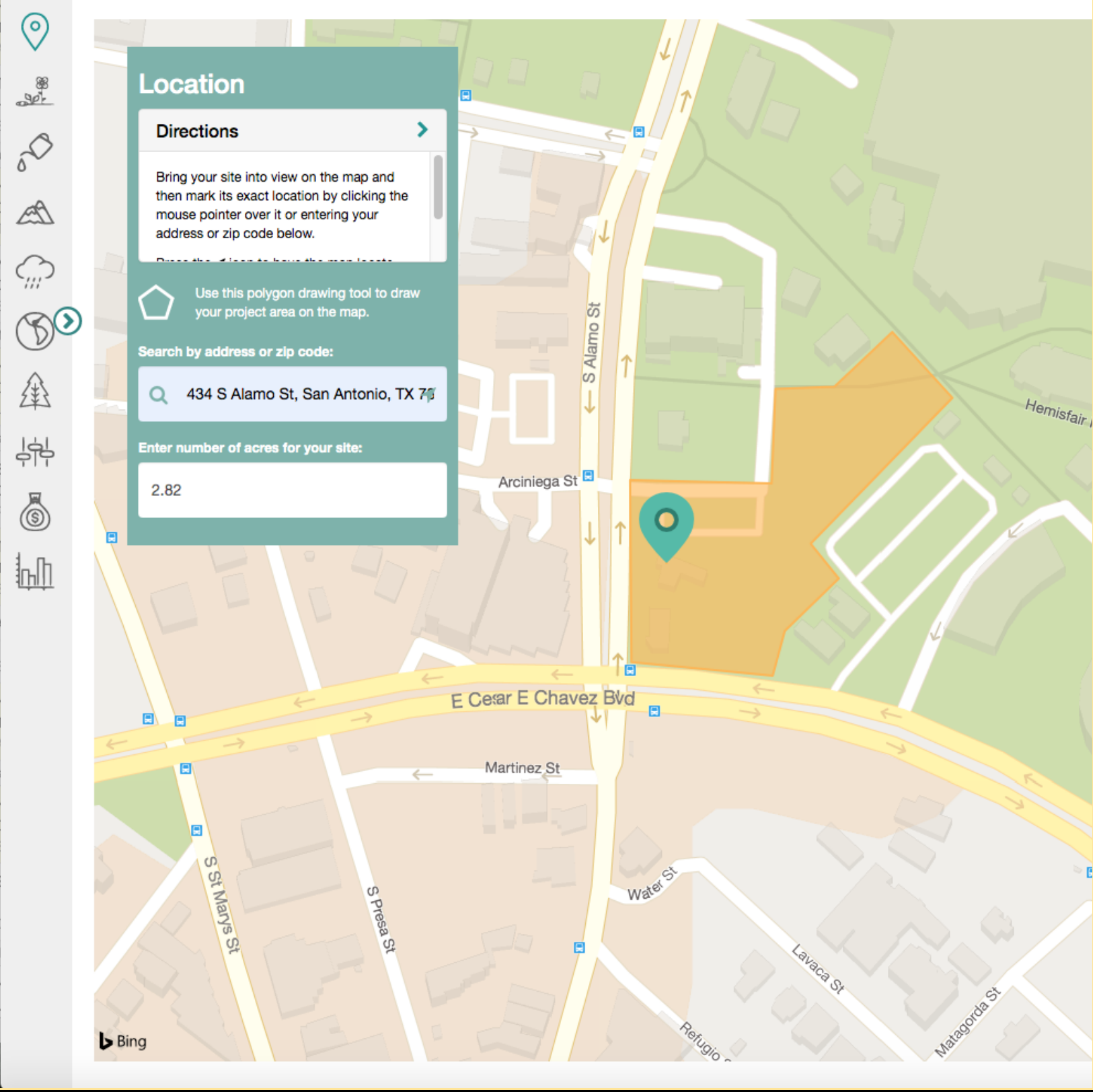

Figure A1: Site Boundary (National Stormwater Calculator) 


\section{SEPA National Stormwater Calculator}

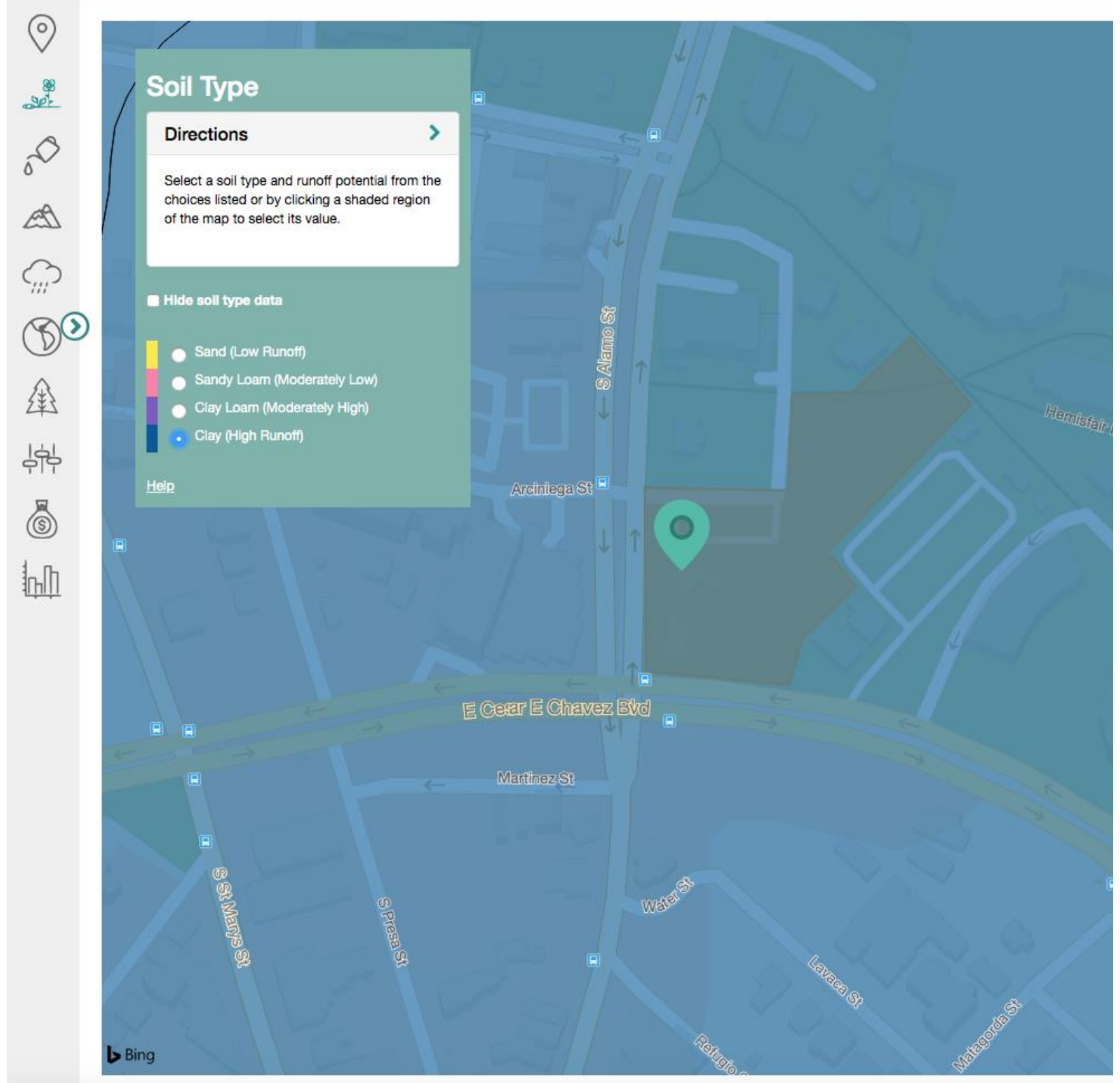

Figure A2: Soil Type (National Stormwater Calculator) 


\section{QEPA National Stormwater Calculator}

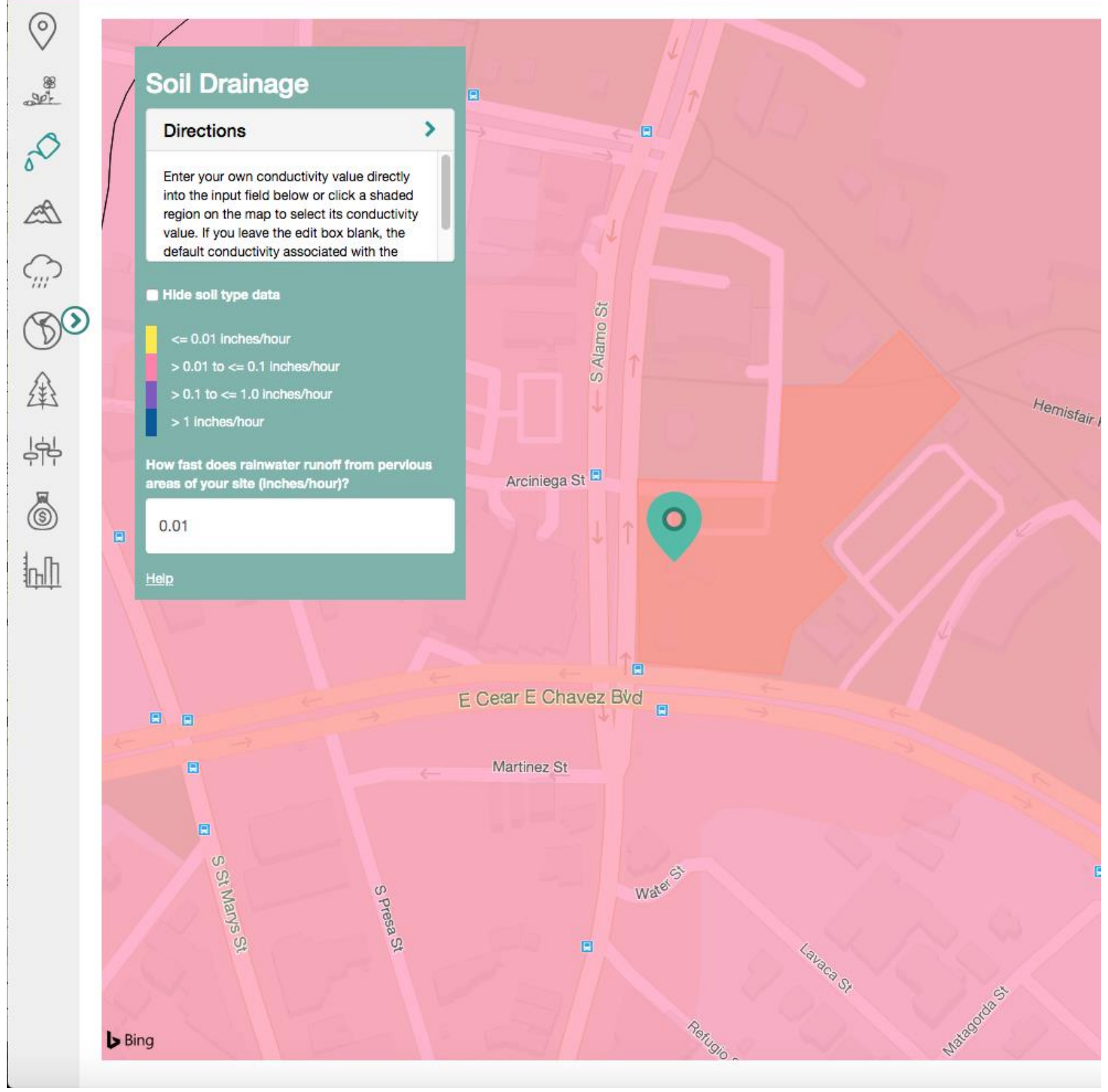

Figure A3: Soil Drainage (National Stormwater Calculator) 


\section{SEPA National Stormwater Calculator}

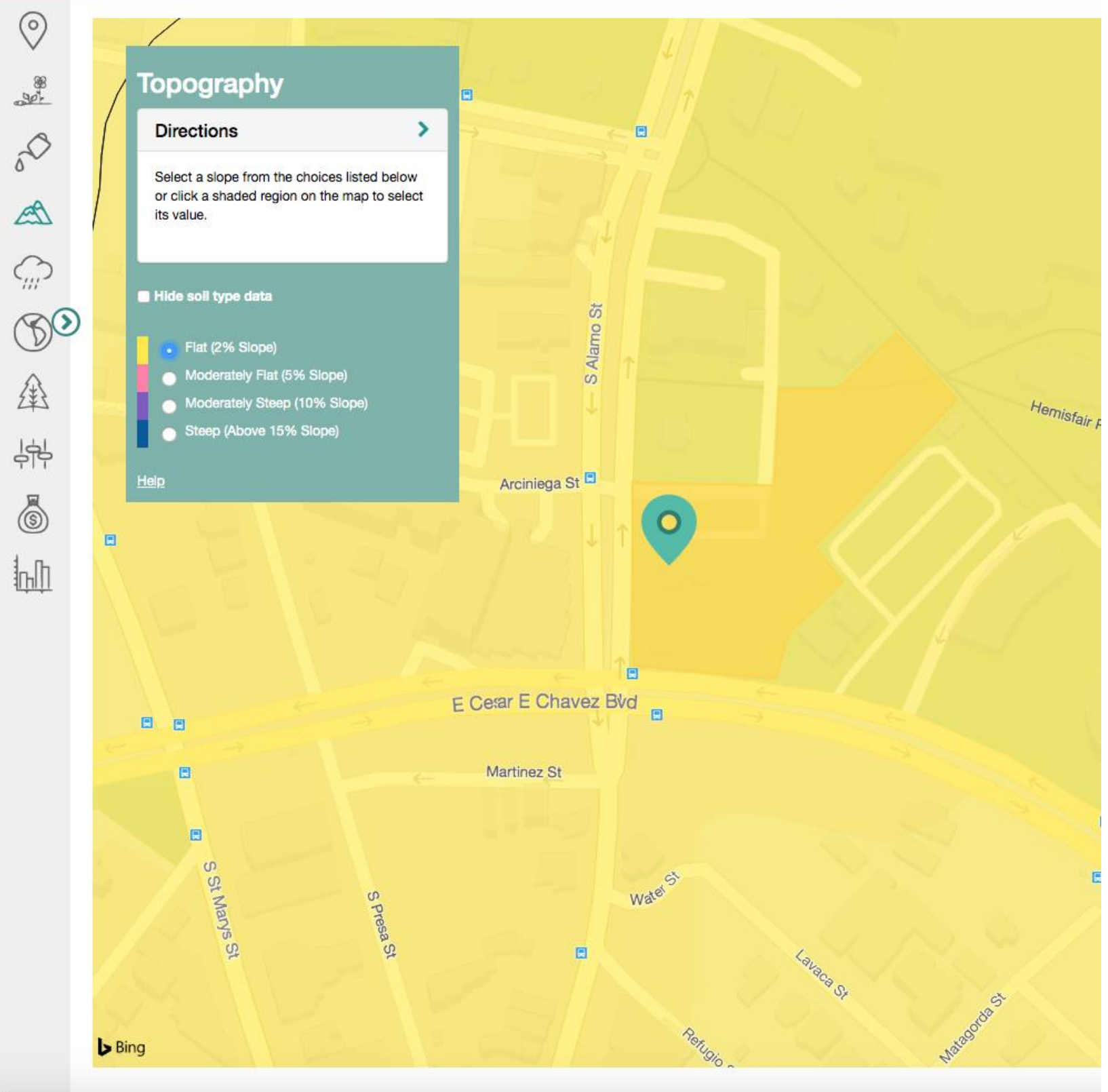

Figure A4: Topography (National Stormwater Calculator) 


\section{QEPANational Stormwater Calculator}

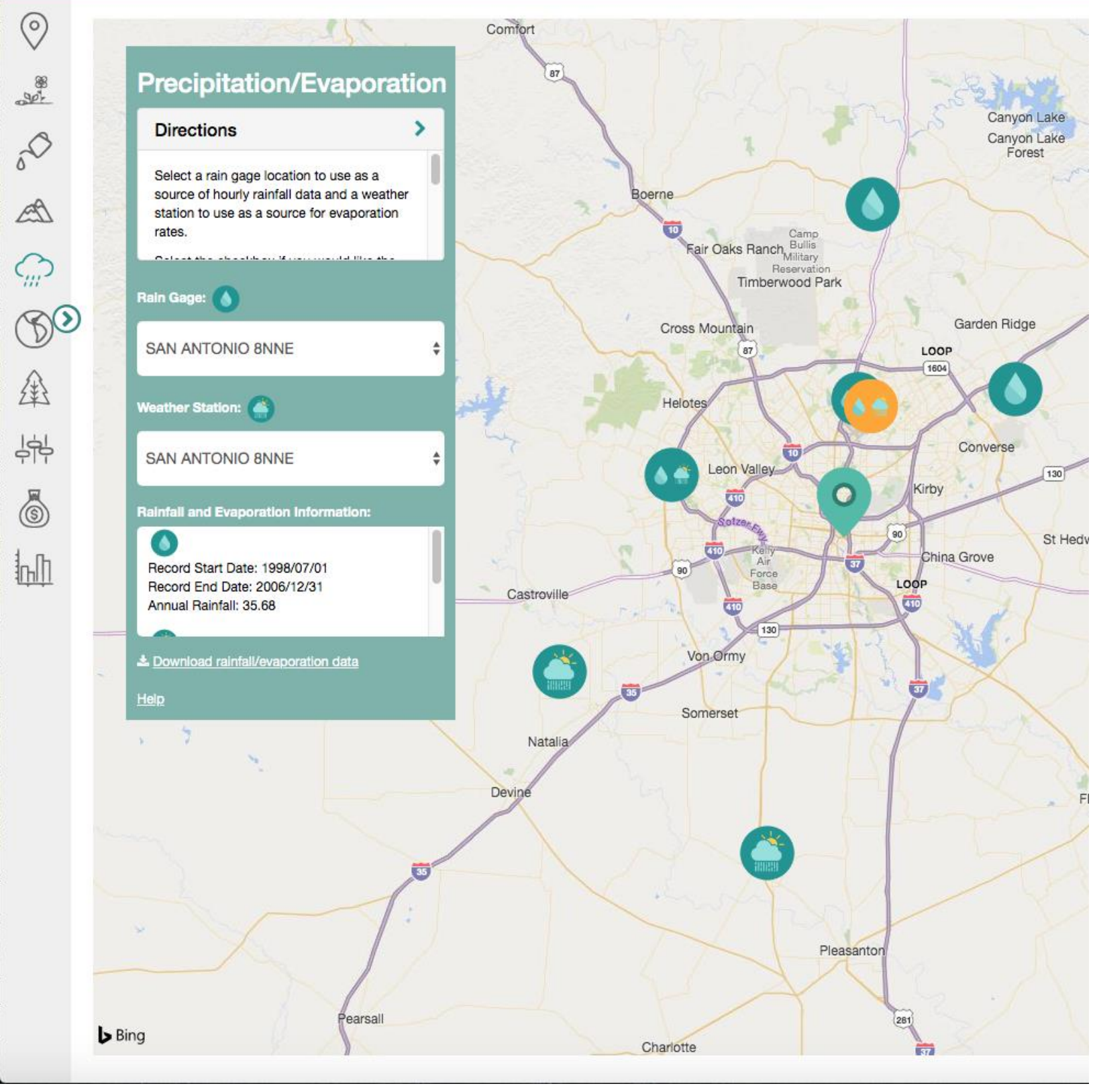

Figure A5: Precipitation/Evaporation (National Stormwater Calculator) 


\section{SEPA National Stormwater Calculator $\quad$ NEW SAVE OPEN RESOURCES CONTACT}

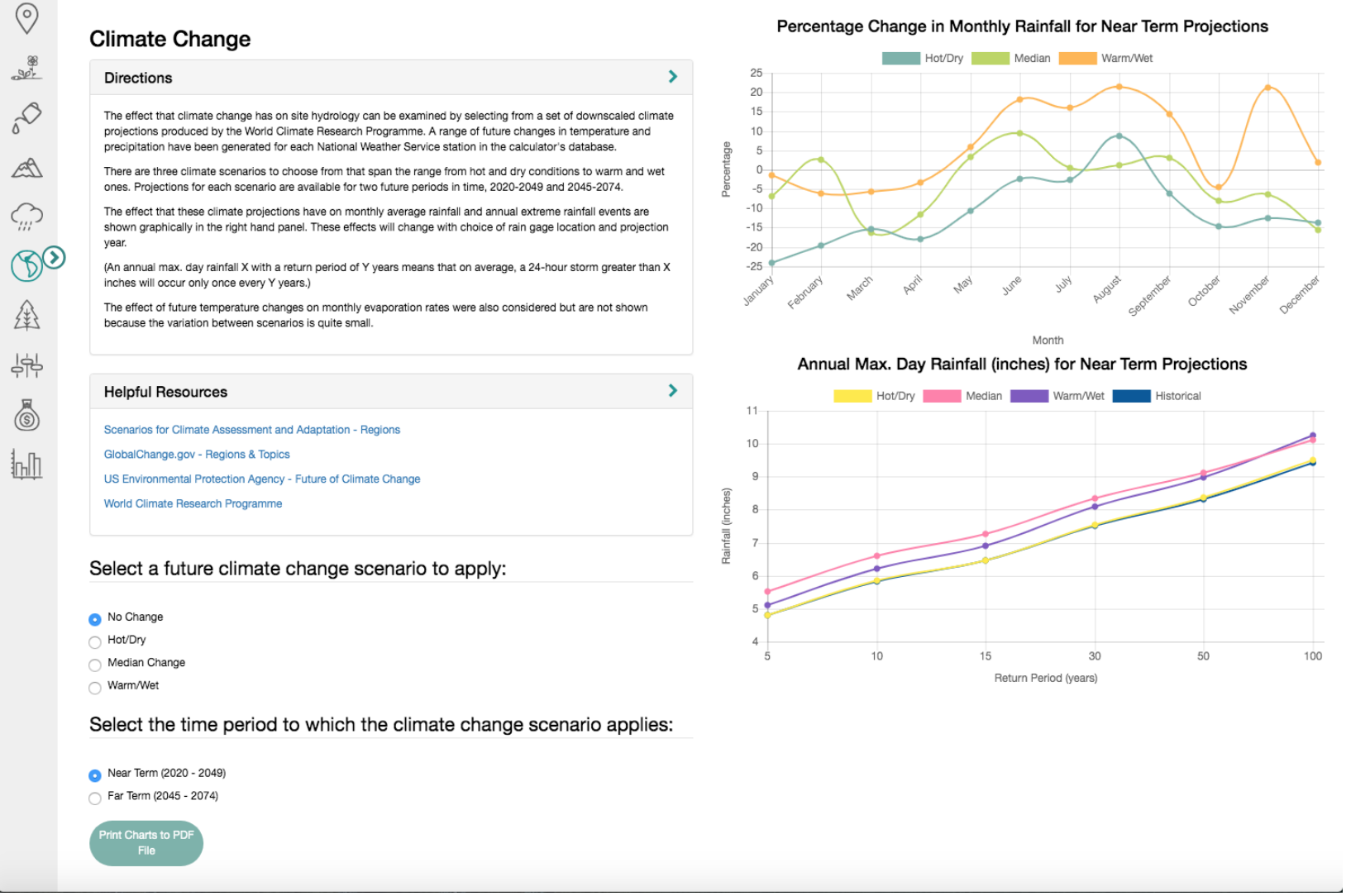

Figure A6: Climate Change (National Stormwater Calculator) 


\section{SEPA National Stormwater Calculator}

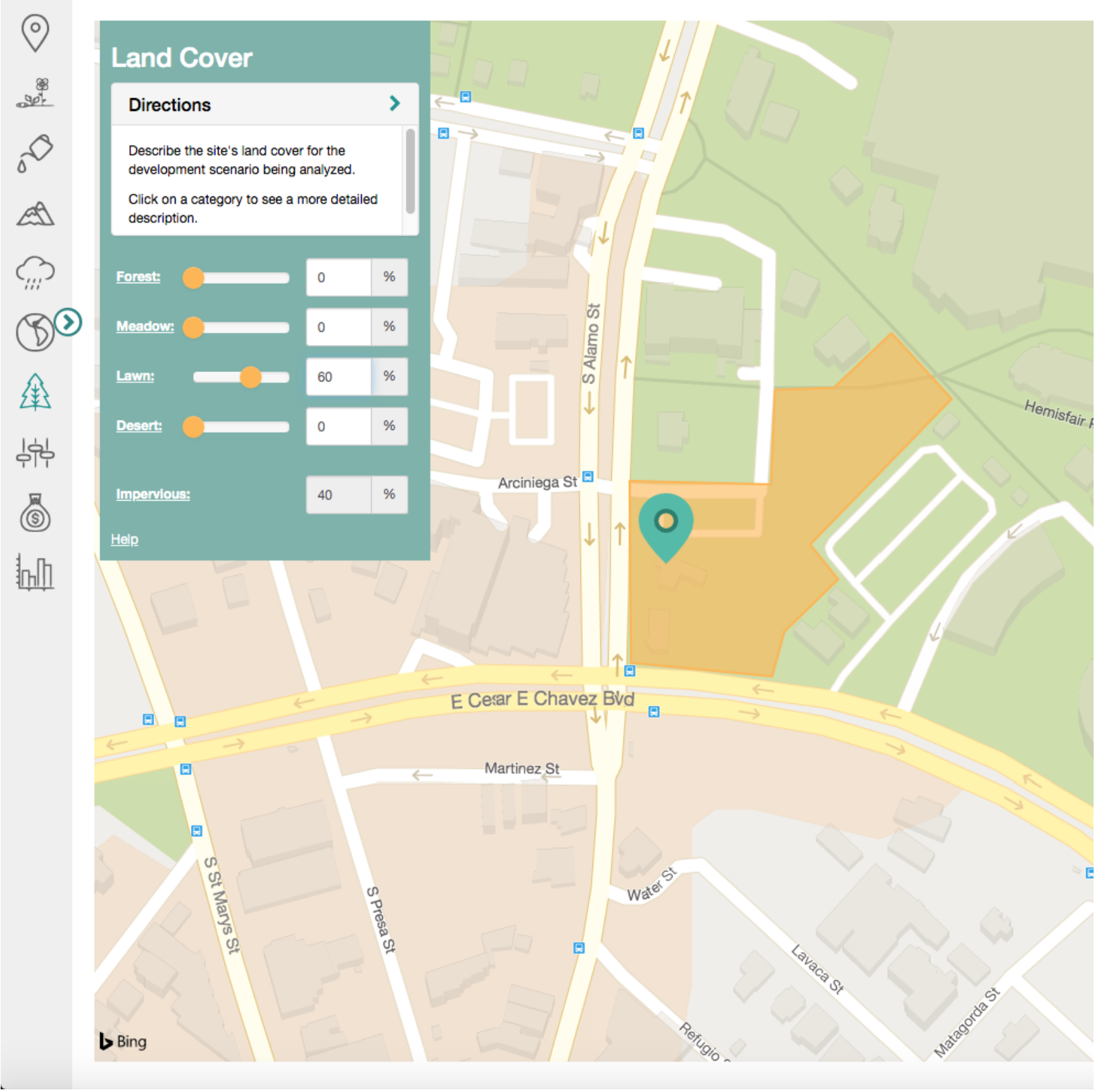

Figure A7: Land Cover (National Stormwater Calculator) 


\section{SEPA National Stormwater Calculator}

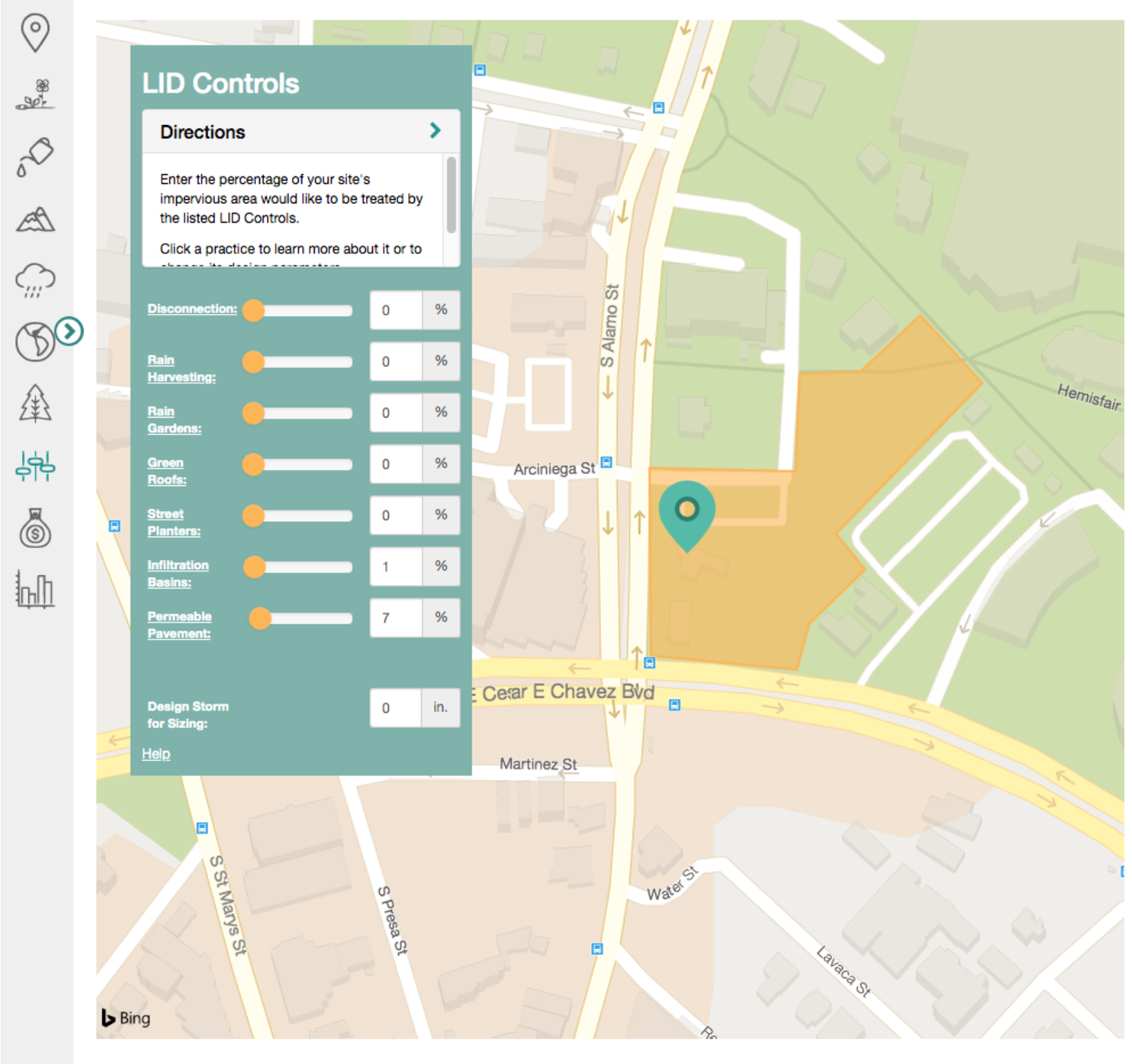

Figure A8: LID Controls (National Stormwater Calculator) 

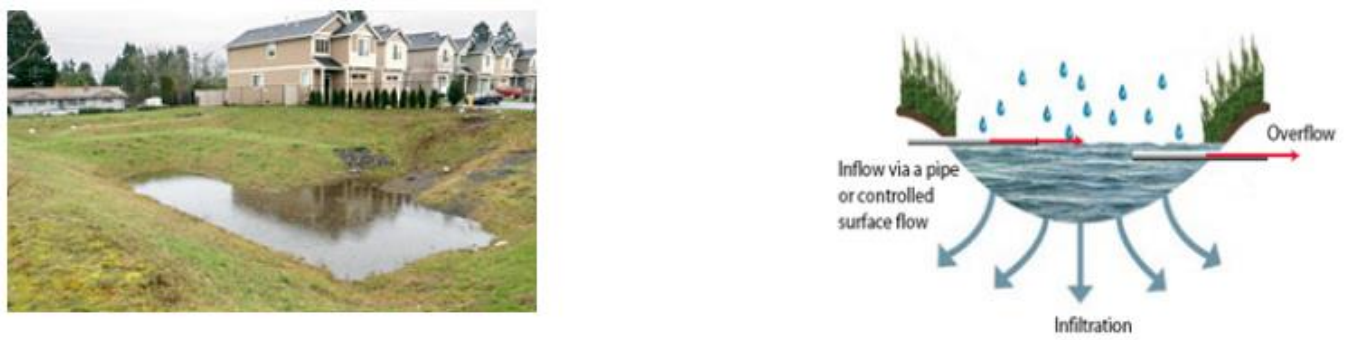

Infiltration basins are shallow depressions filled with grass or other natural vegetation that capture runoff from adjoining areas and allow it to infiltrate into the soil.

The calculator assumes that the infiltration rate from the basin is the same as for site's native soil.

The basin's Capture Ratio is the area of the basin relative to the impervious area whose runoff it captures.

Learn More

Basin Depth:

$\%$ Capture Radio:

Pre-Treatment

Figure A9: LID Controls - Infiltration Basins (National Stormwater Calculator) 

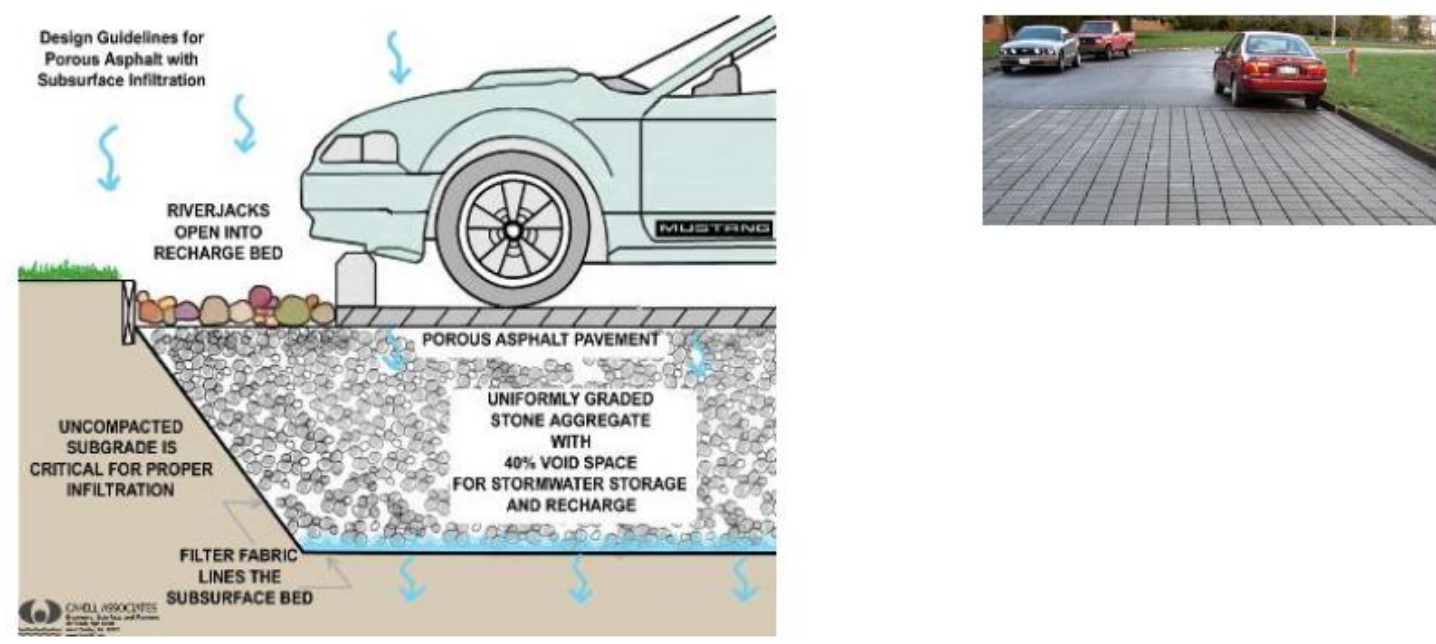

Continuous Permeable Pavement systems are excavated areas filled with gravel and paved over with a porous concrete or asphalt mix.

Modular Block systems are similar except that permeable block pavers are used instead.

Normally all rainfall will immediately pass through the pavement into the gravel storage layer below it where it can infiltrate at natural rates into the site's native soil.

Pavement layers are usually 4 to 6 inches in height while the gravel storage layer is typically 6 to 18 inches high.

The Capture Ratio is the percent of the treated area (street or parking lot) that is replaced with permeable pavement.

Learn More

Pavement

Thickness:

Gravel Layer

Thickness:

\% Capture Ratio:

$6 \quad$ in

18

100

$\%$

Pre-Treatment

Size for Design Storm

Figure A10: LID Controls - Permeable Pavement (National Stormwater Calculator) 
Appendix B

Survey Results

\section{Q1 - Are you a:}

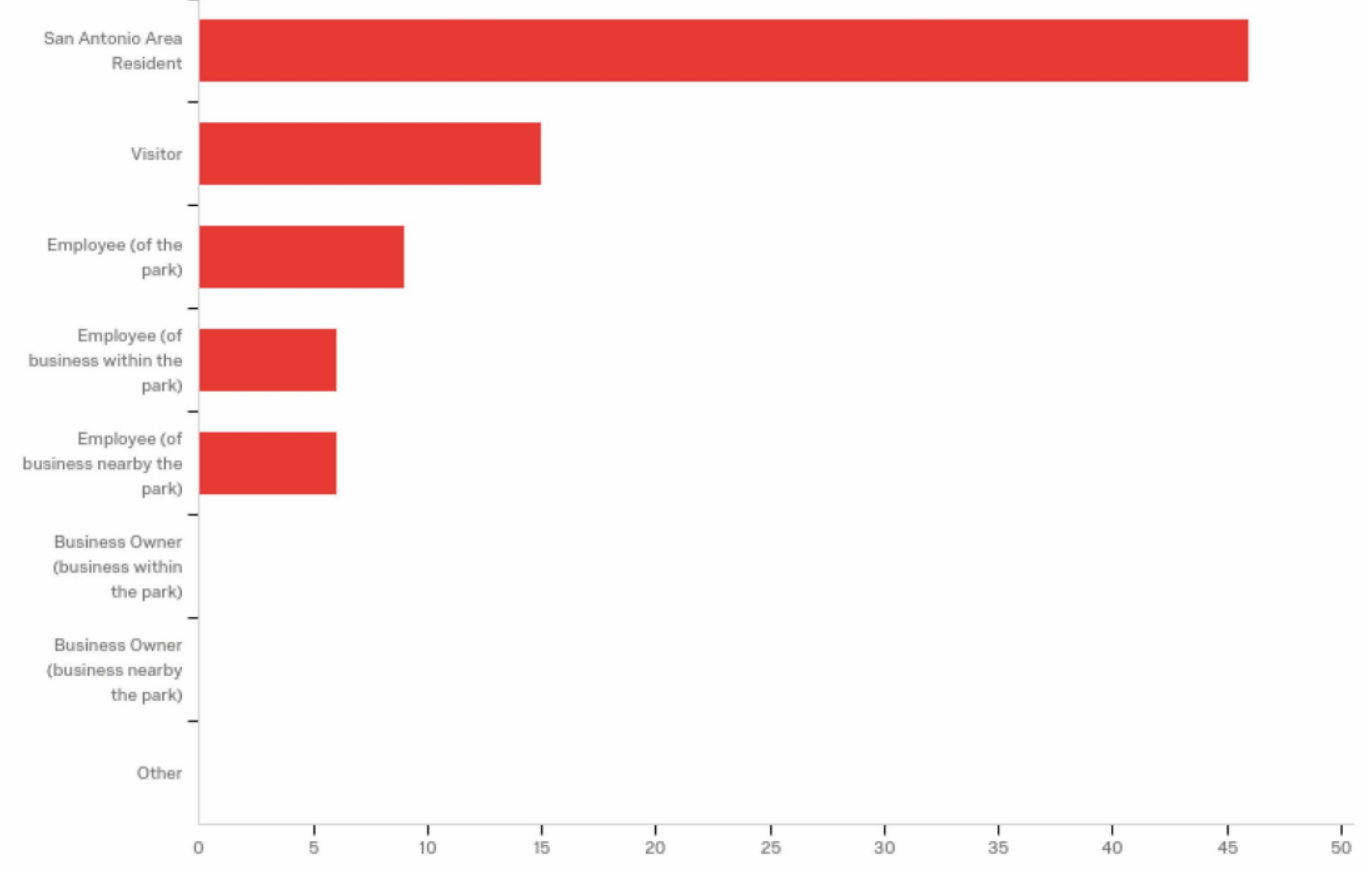


Q2 - For what purpose are you coming to the garden?

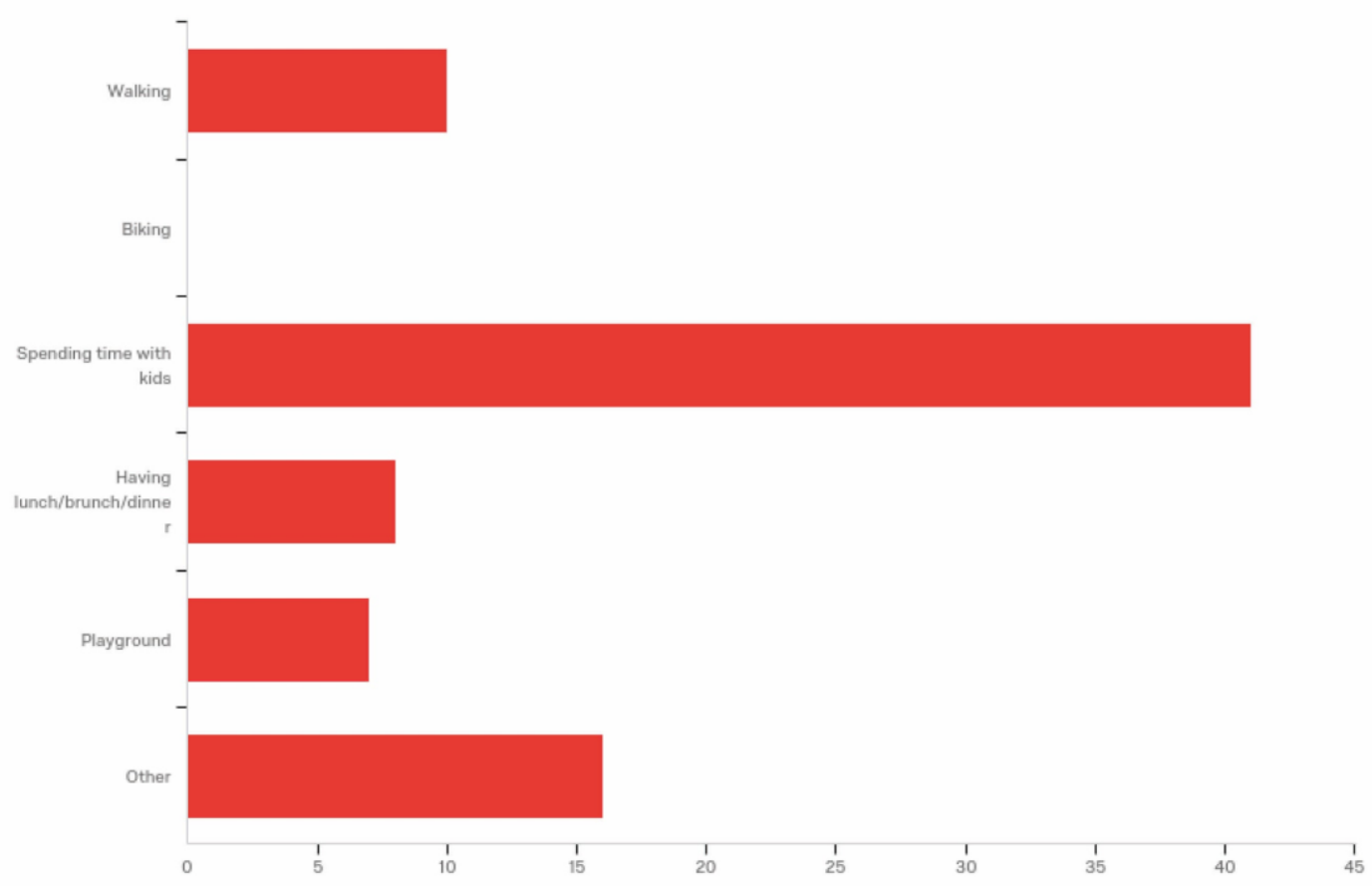


Q3 - Approximately how often do you visit the garden?

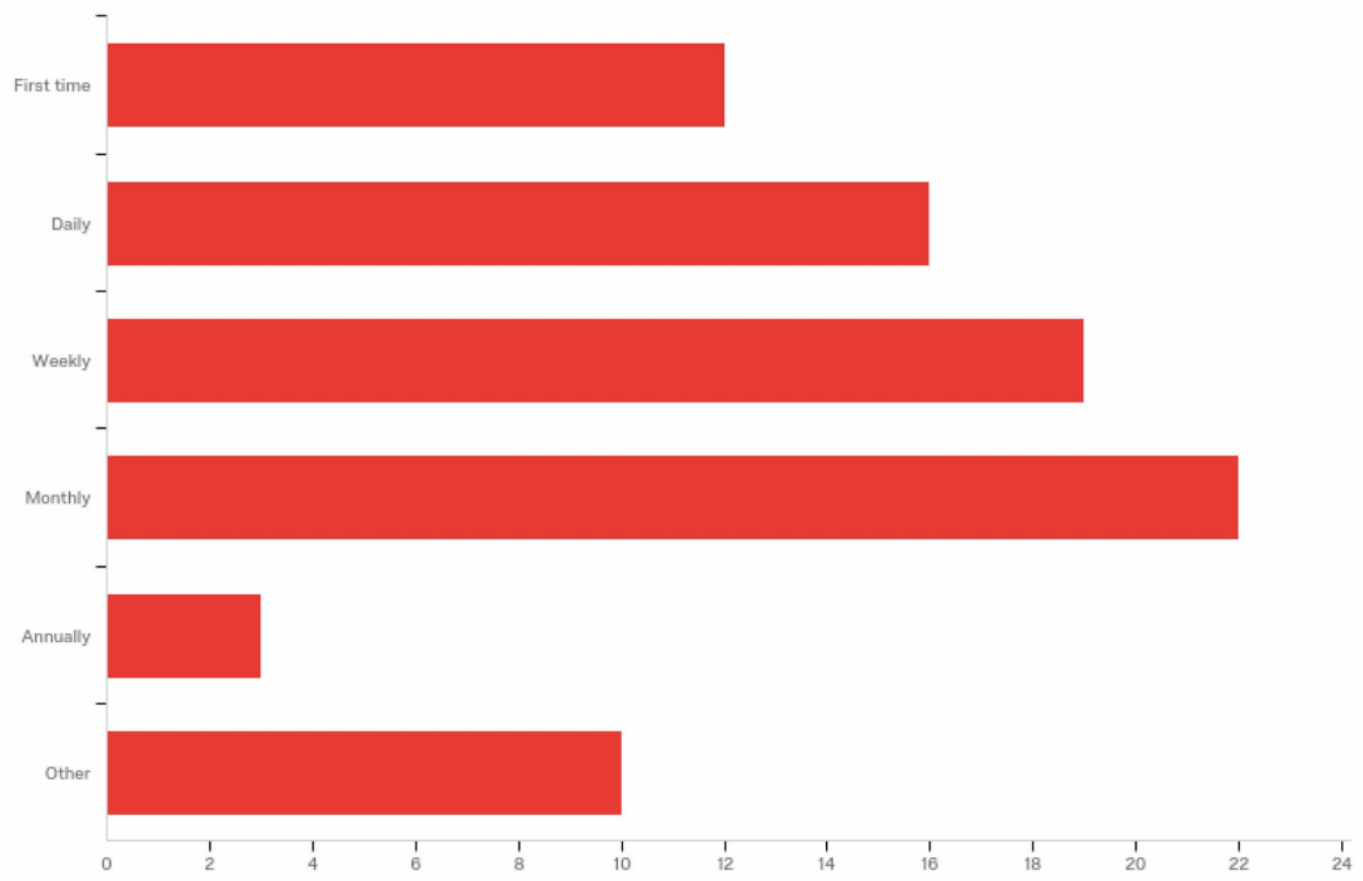


Q4 - What time of day do you typically visit the garden?

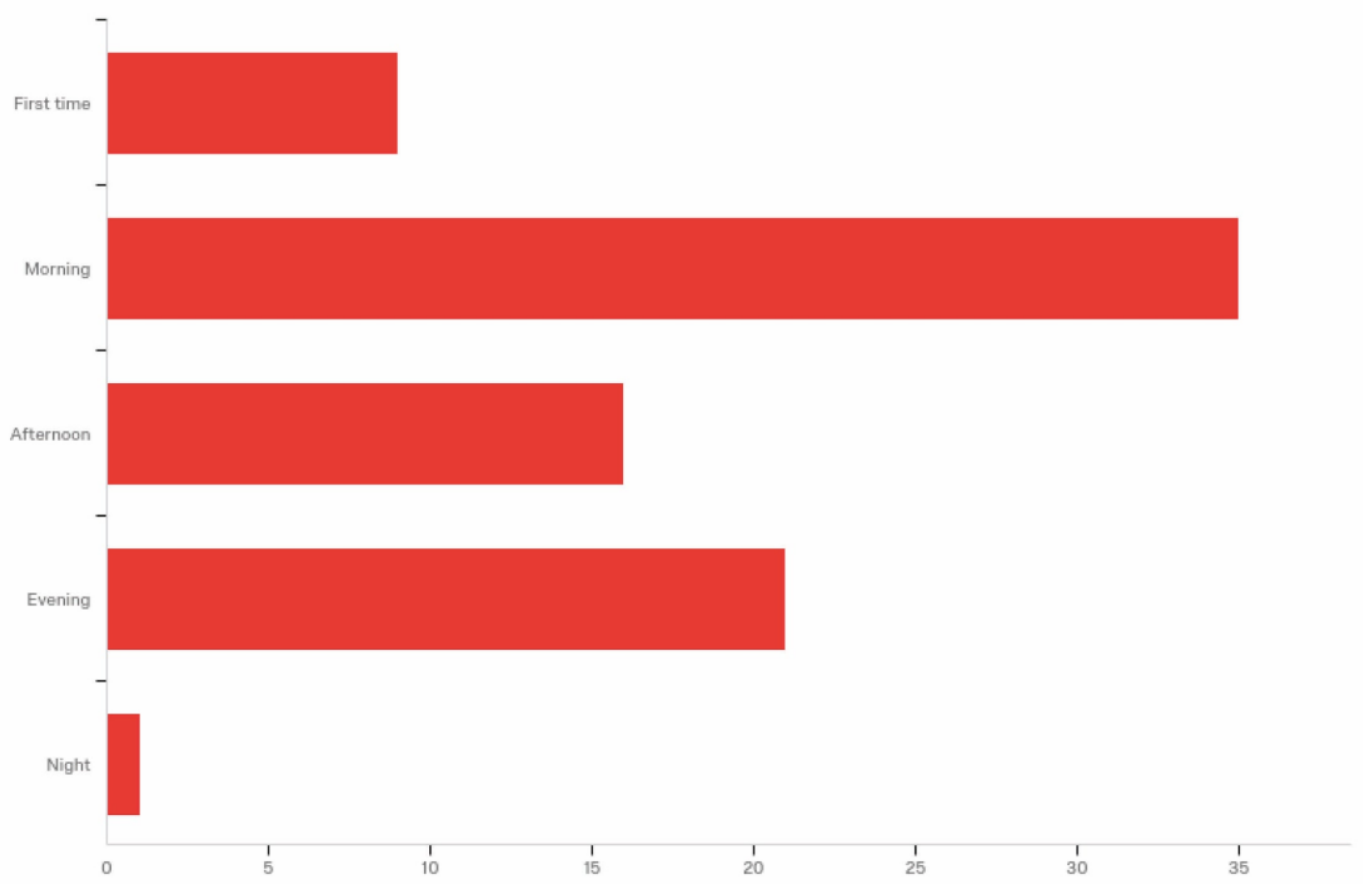


Q5 - What garden elements do you most often use?

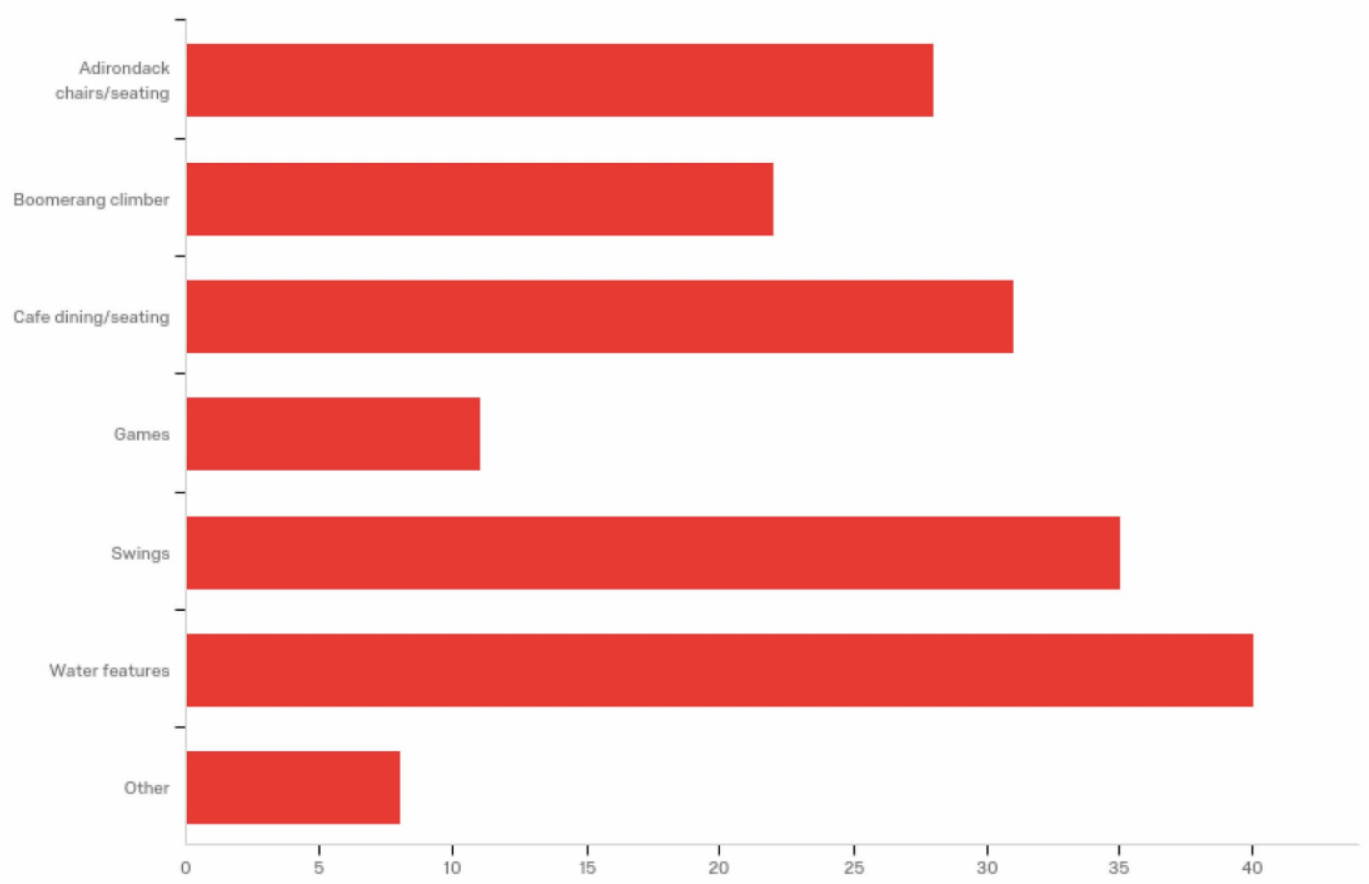


Q6 - How do you typically get to the garden?

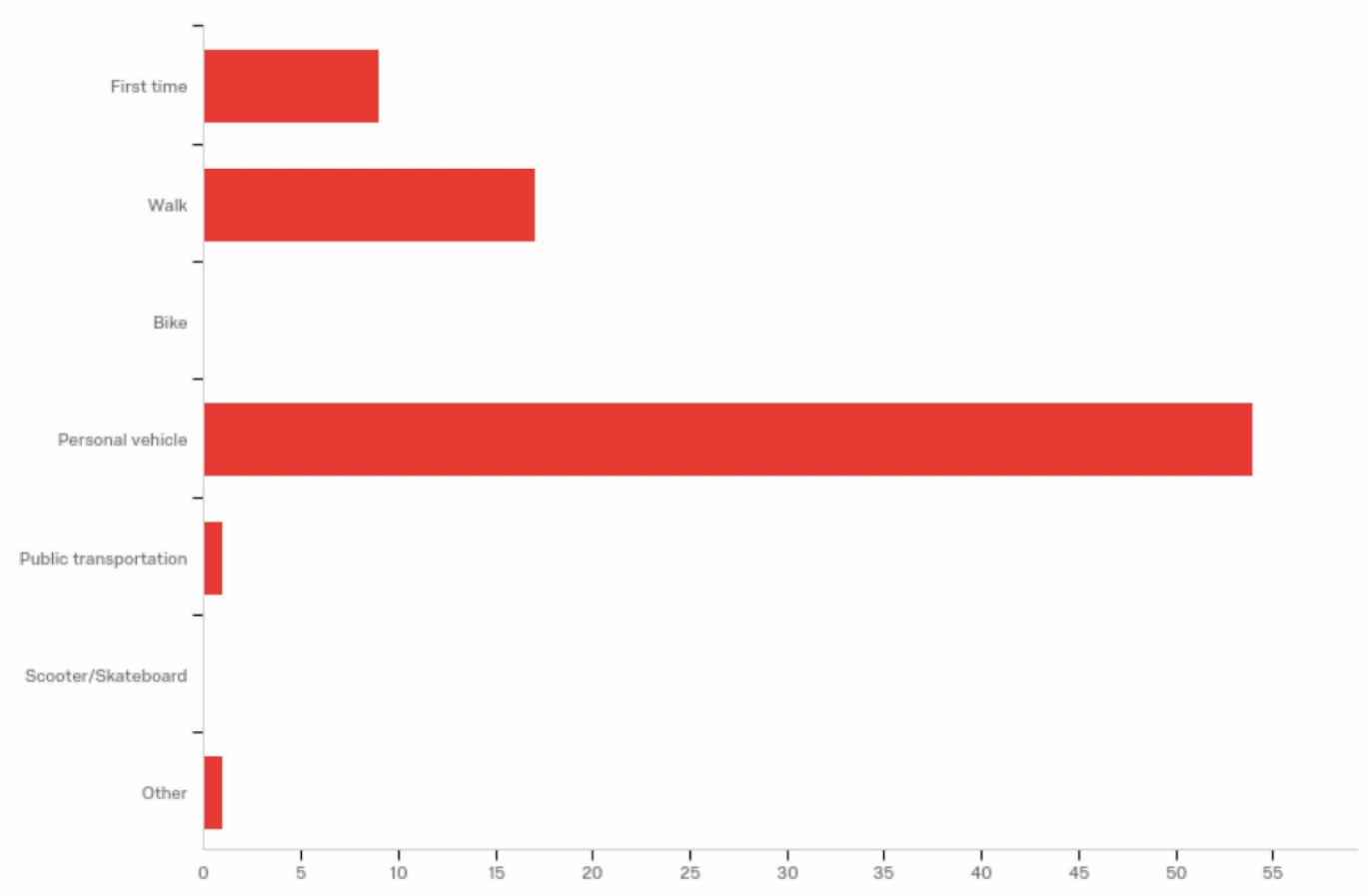


Q7 - How long did it/does it typically take you to get the Yanaguana Garden?

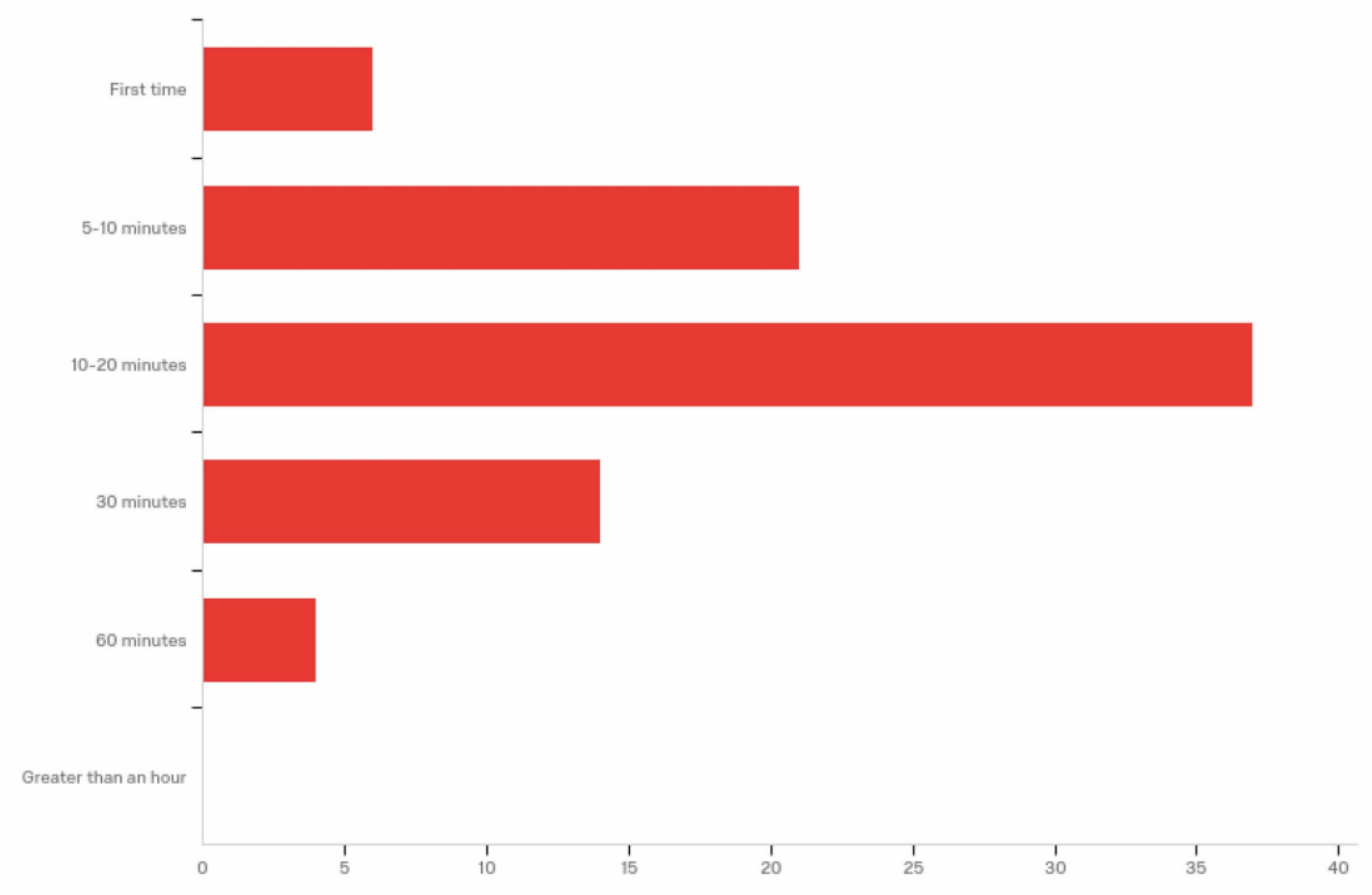


Q8 - Are you able to access/use/enjoy all play features?

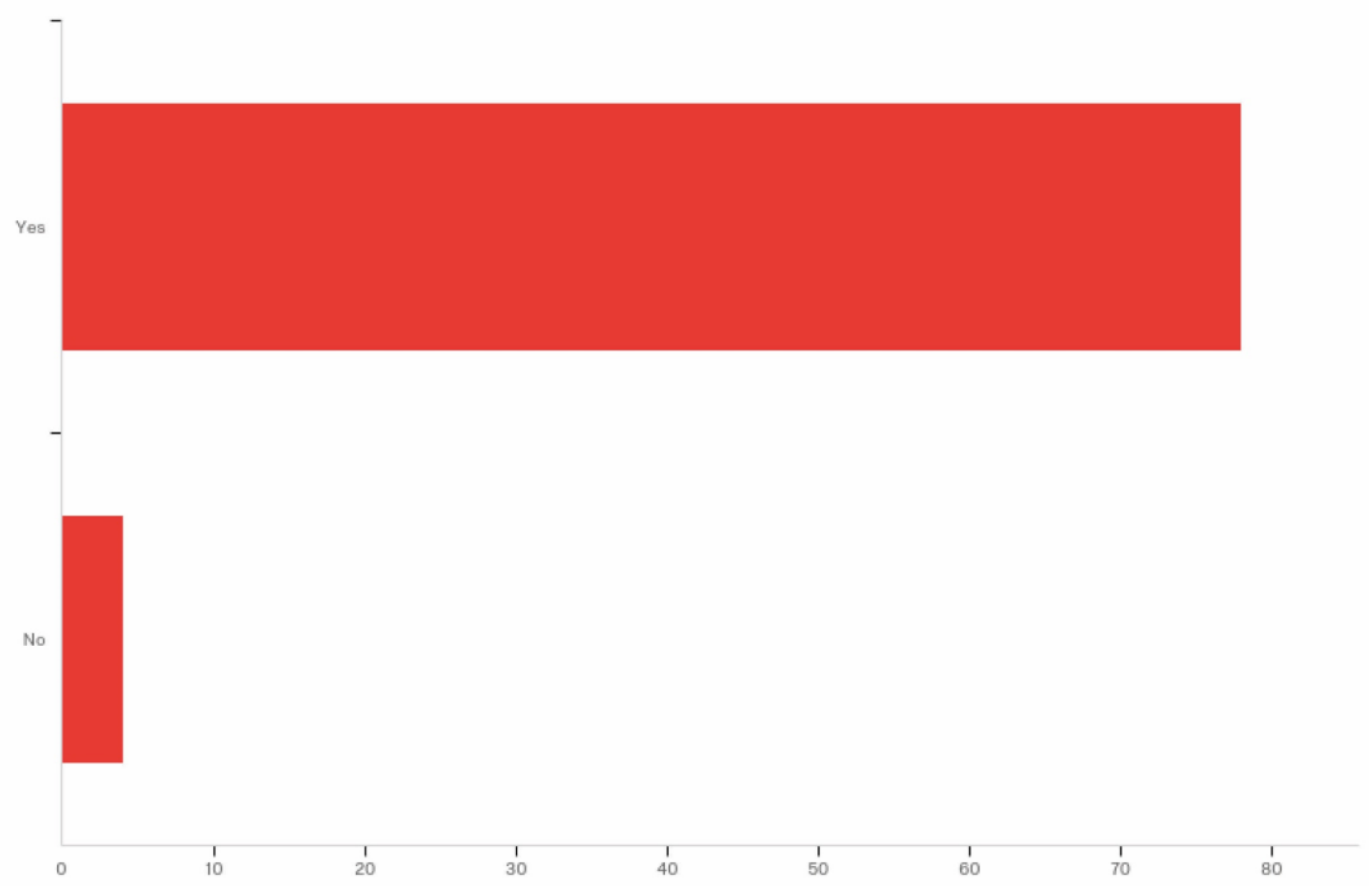


Q9 - Do you have a disability or condition that may affect your ability to utilize the play and garden features?

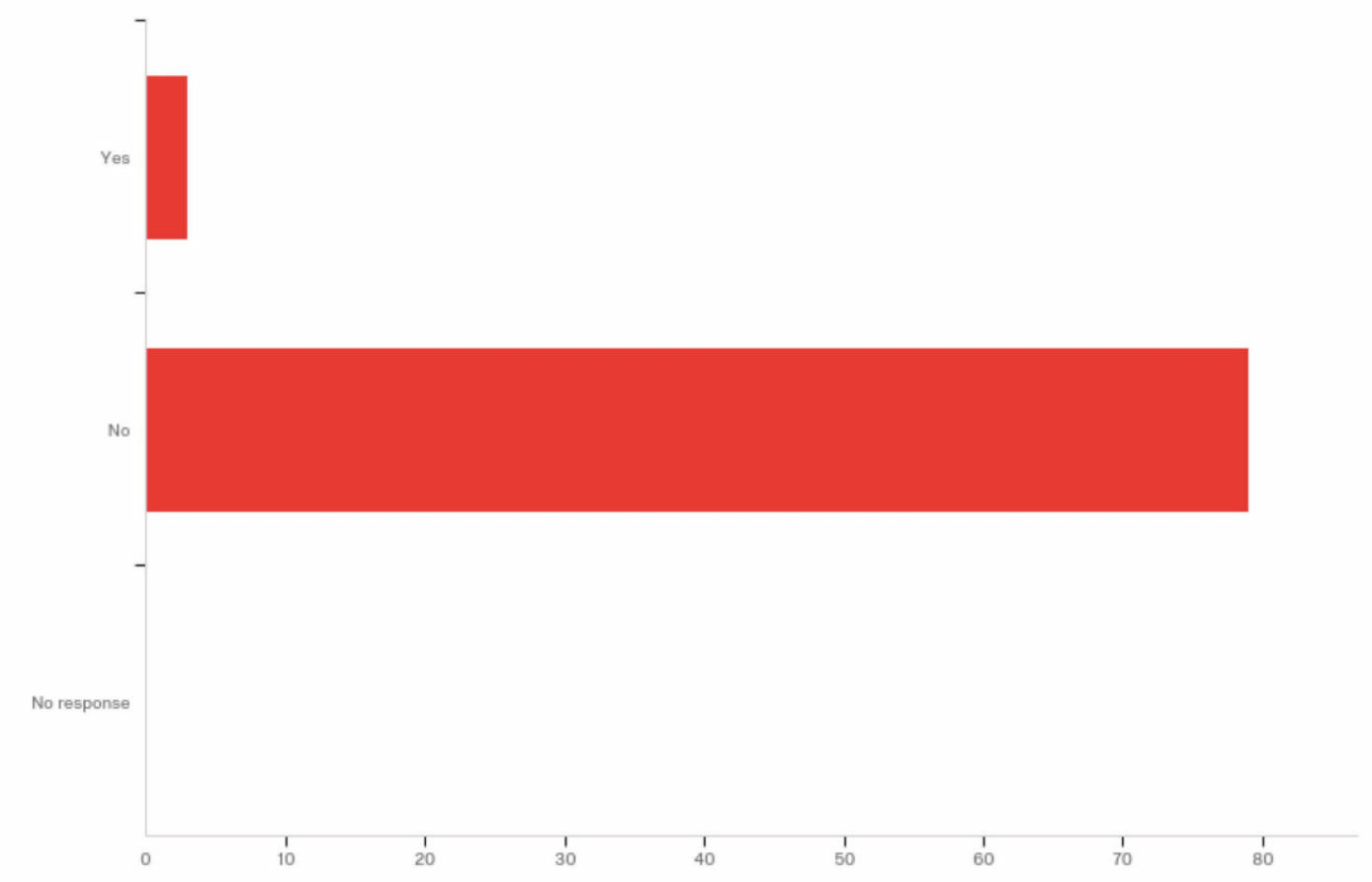


Q10 - How would you rate the aesthetic quality (beauty or attractiveness) of the garden? ( 1 indicates the lowest and 5 indicates the highest)

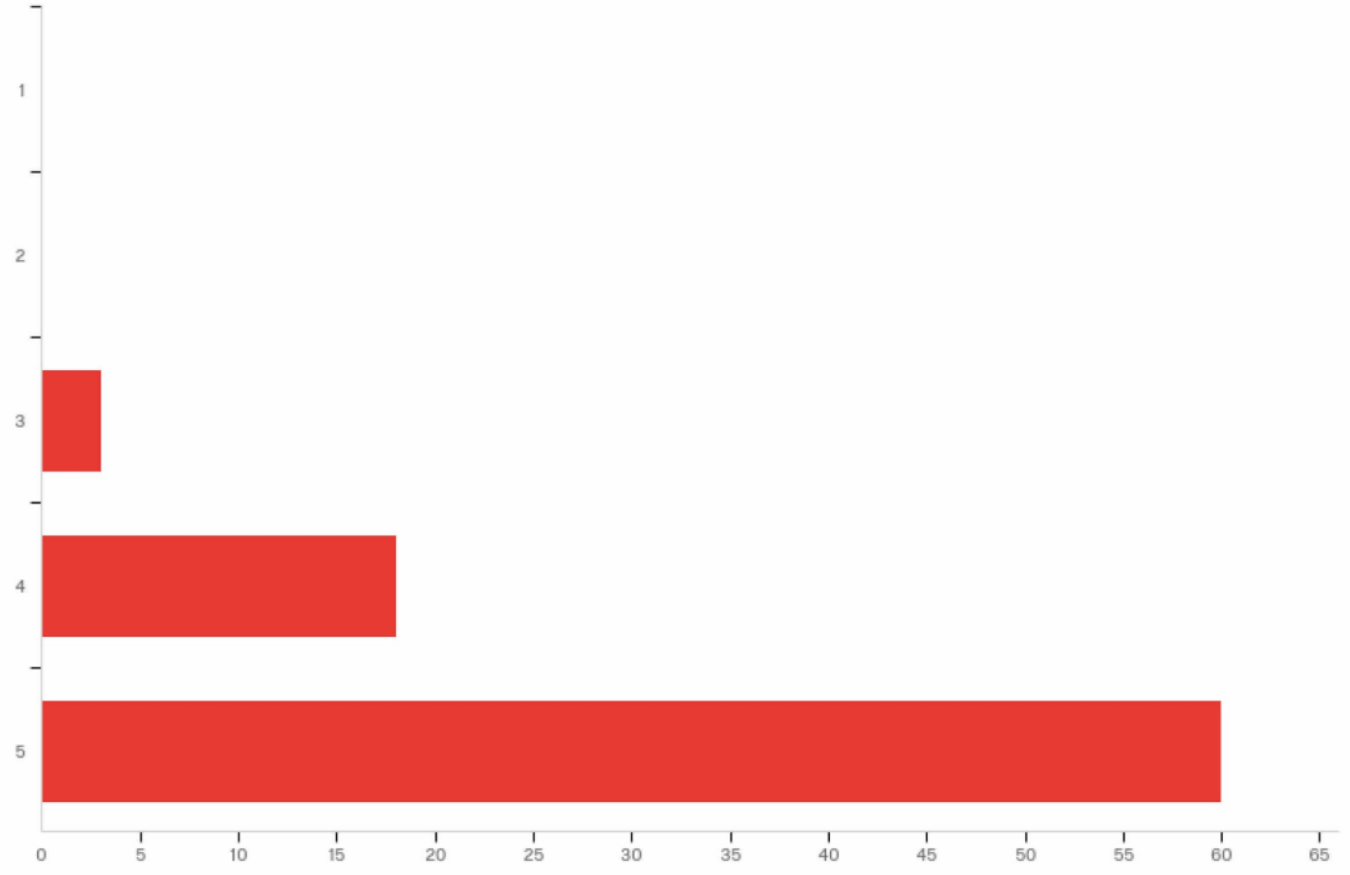


Q11 - Have you attended any events at the park/garden? (Bend and Brew, Outdoor Film Series, Story Time and Book Garden, Art in the Park, Fiesta 2019, etc.)
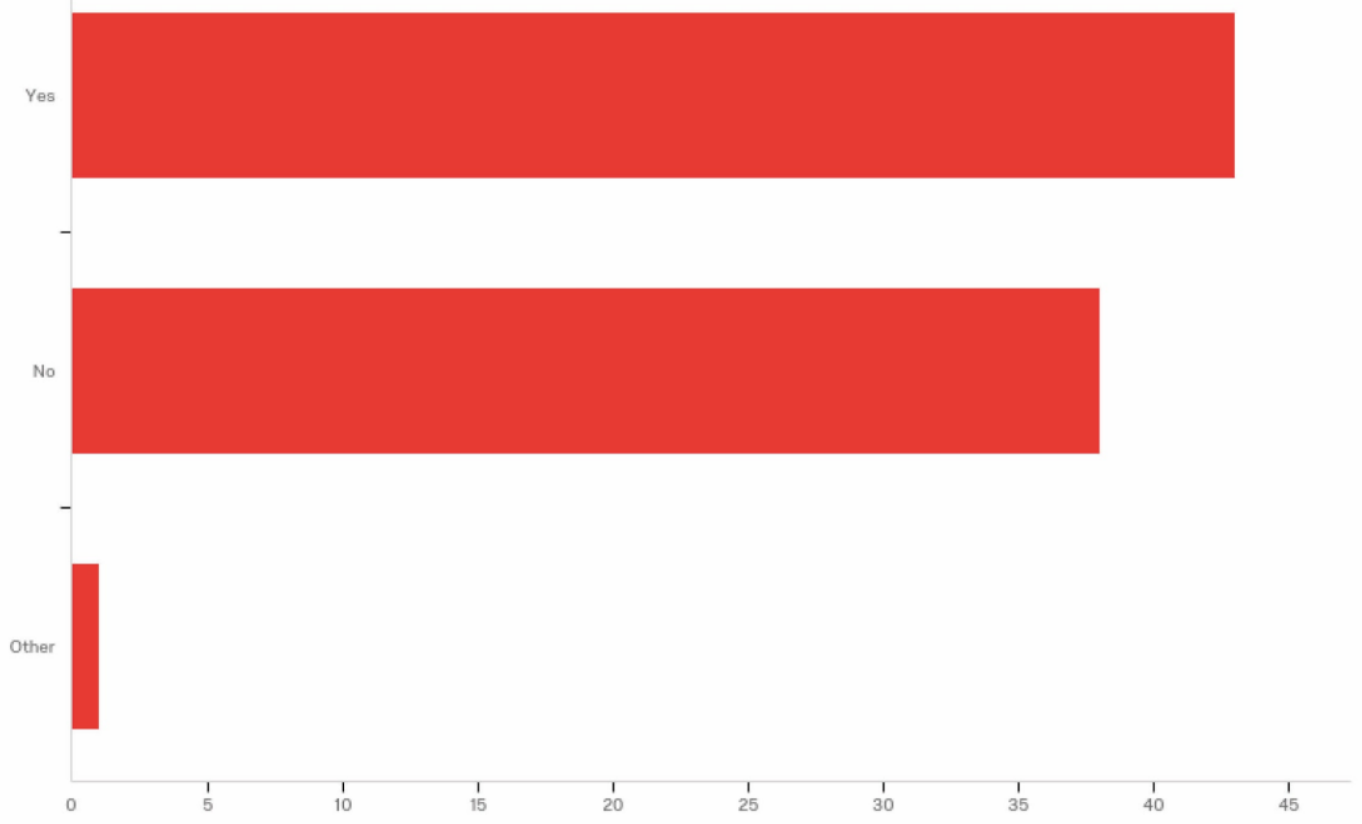
Q12 - How many of these events have you attended at the garden since its opening in October of 2015?

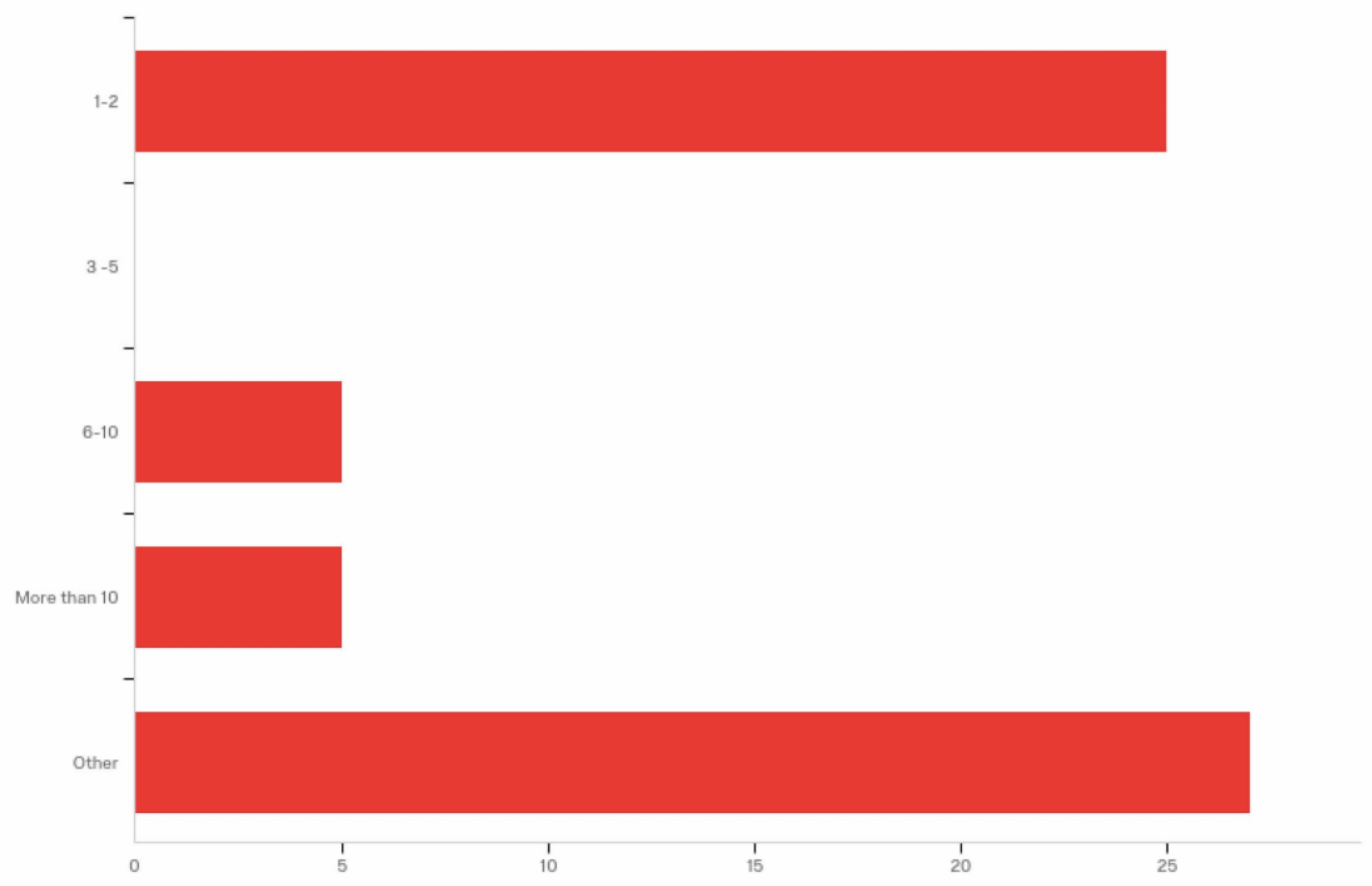


Q13 - Have you visited any nearby businesses/restaurants as part of your visit to the garden?

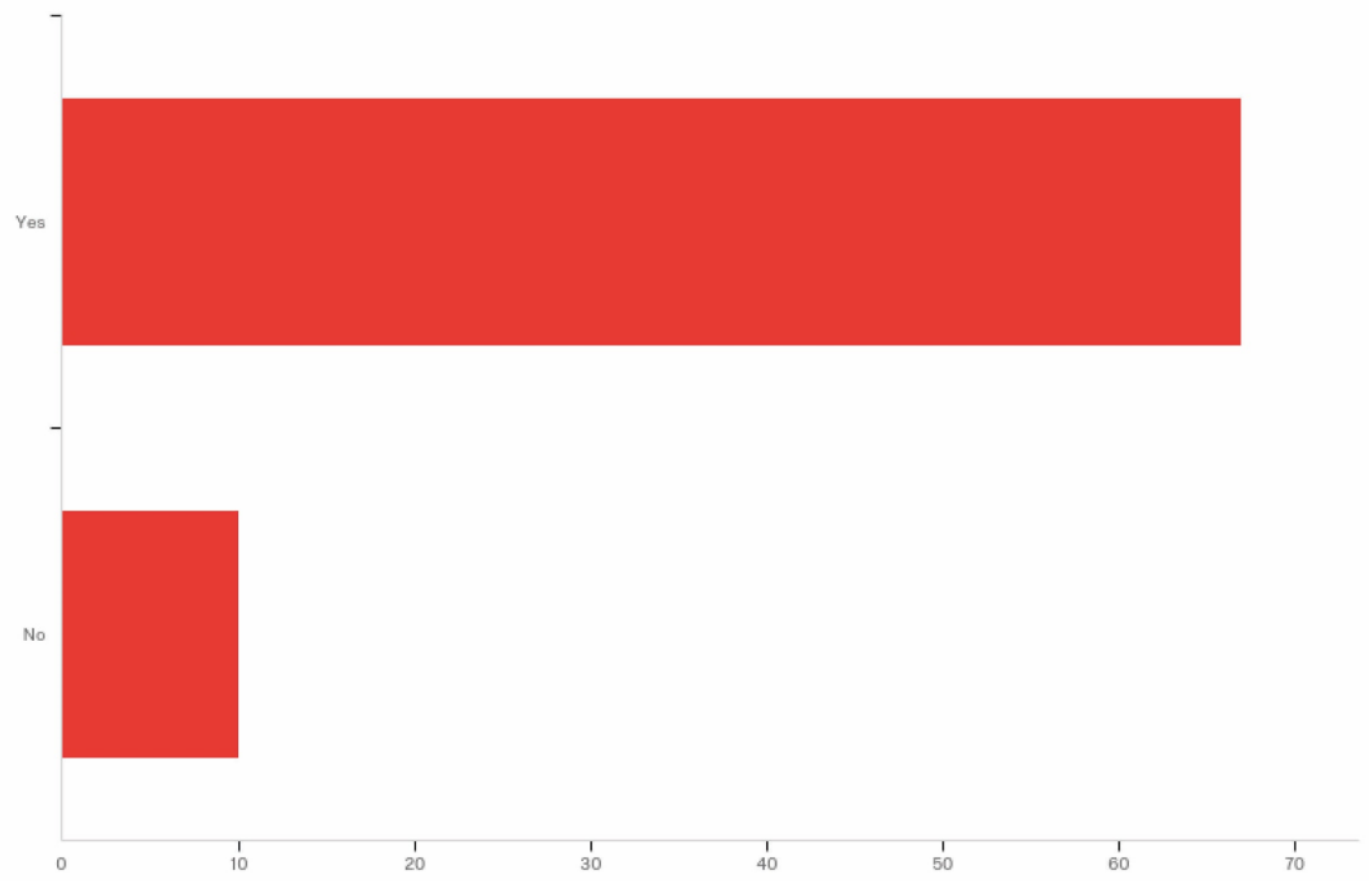


Q14 - How often do you visit nearby businesses/restaurants as part of your visit to the garden?

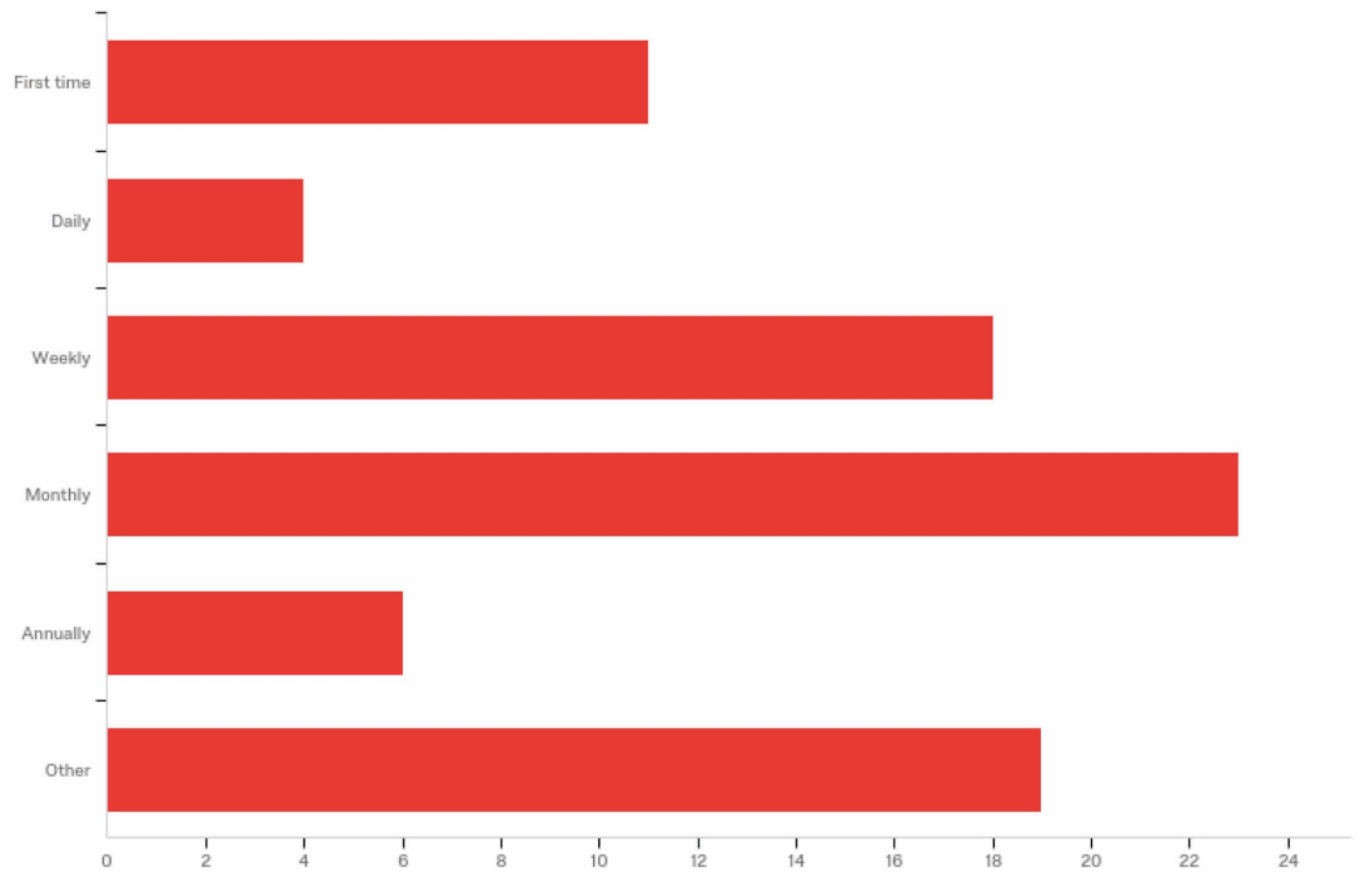




\section{Q15\#1 - Could you rate the following statements regarding your experience with the Yanaguana Garden? (1 i... - Ranking}

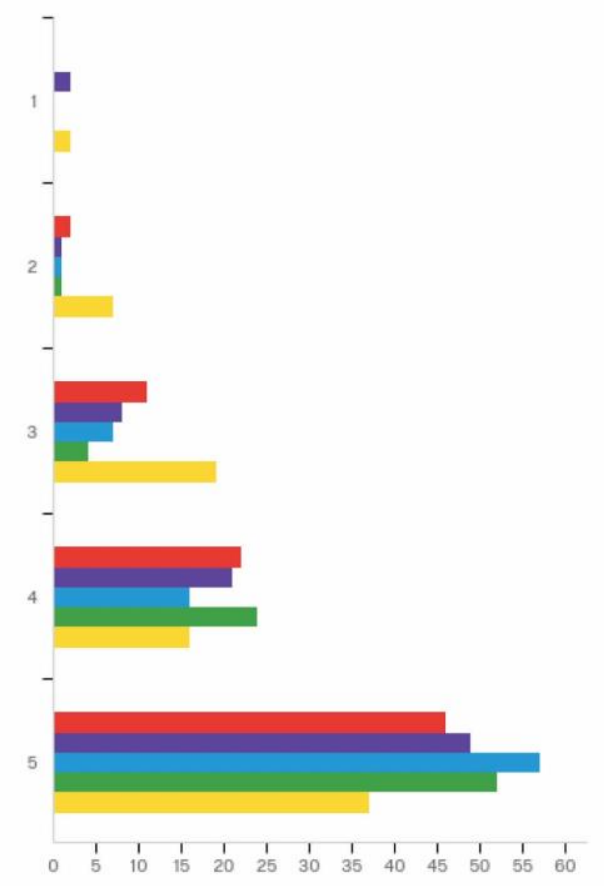

Visiting the garden increases my quality of life (QoL)/well-being

Access to the garden is easy

The garden provides diverse recreational activities

- I feel safe and secure when I am in the garden

The art in the garden has helped me understand its cultural and historical ... 
QID21 - What is your age?

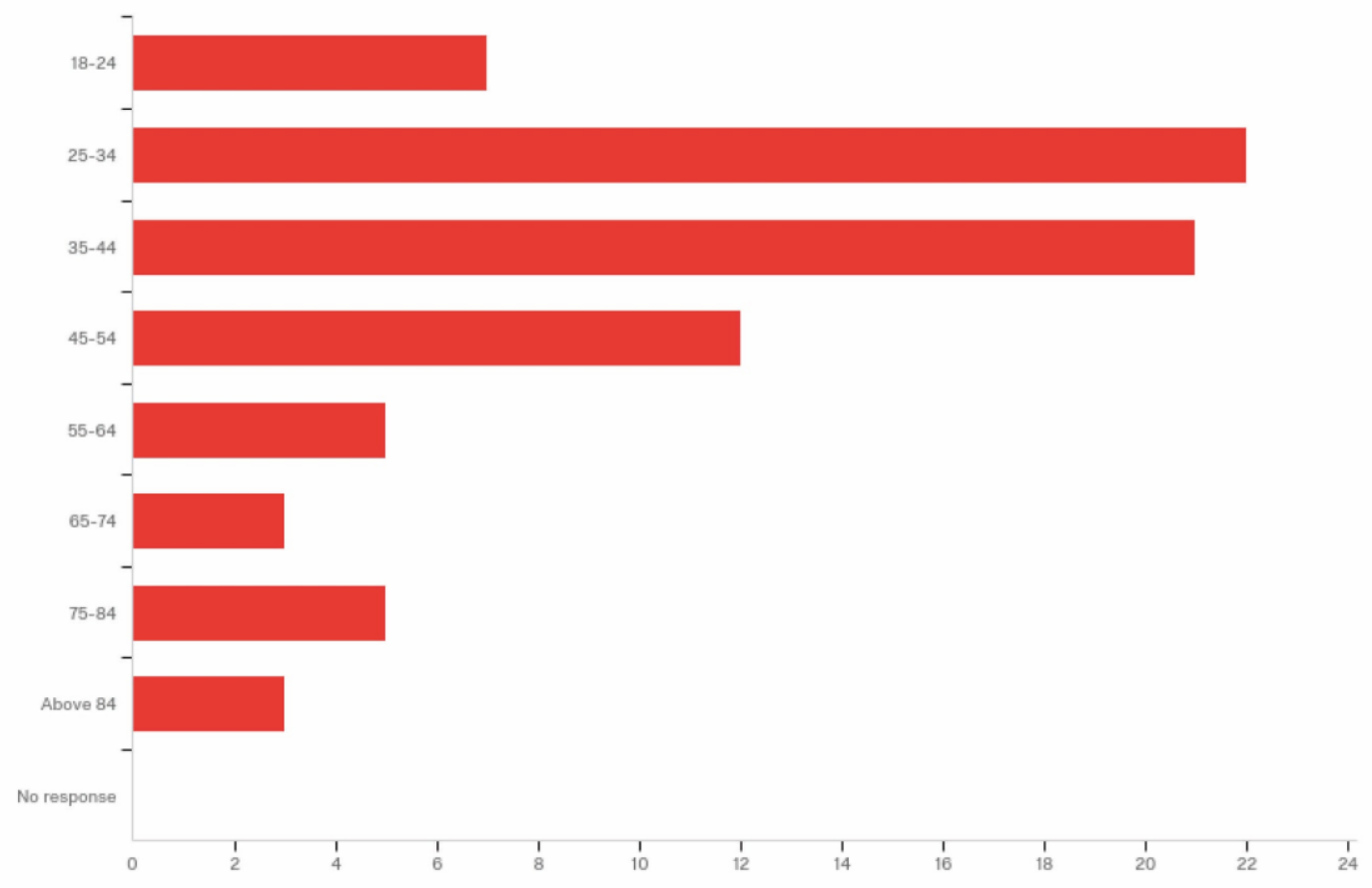


QID24 - Are you of Hispanic, Latino, or Spanish origin?

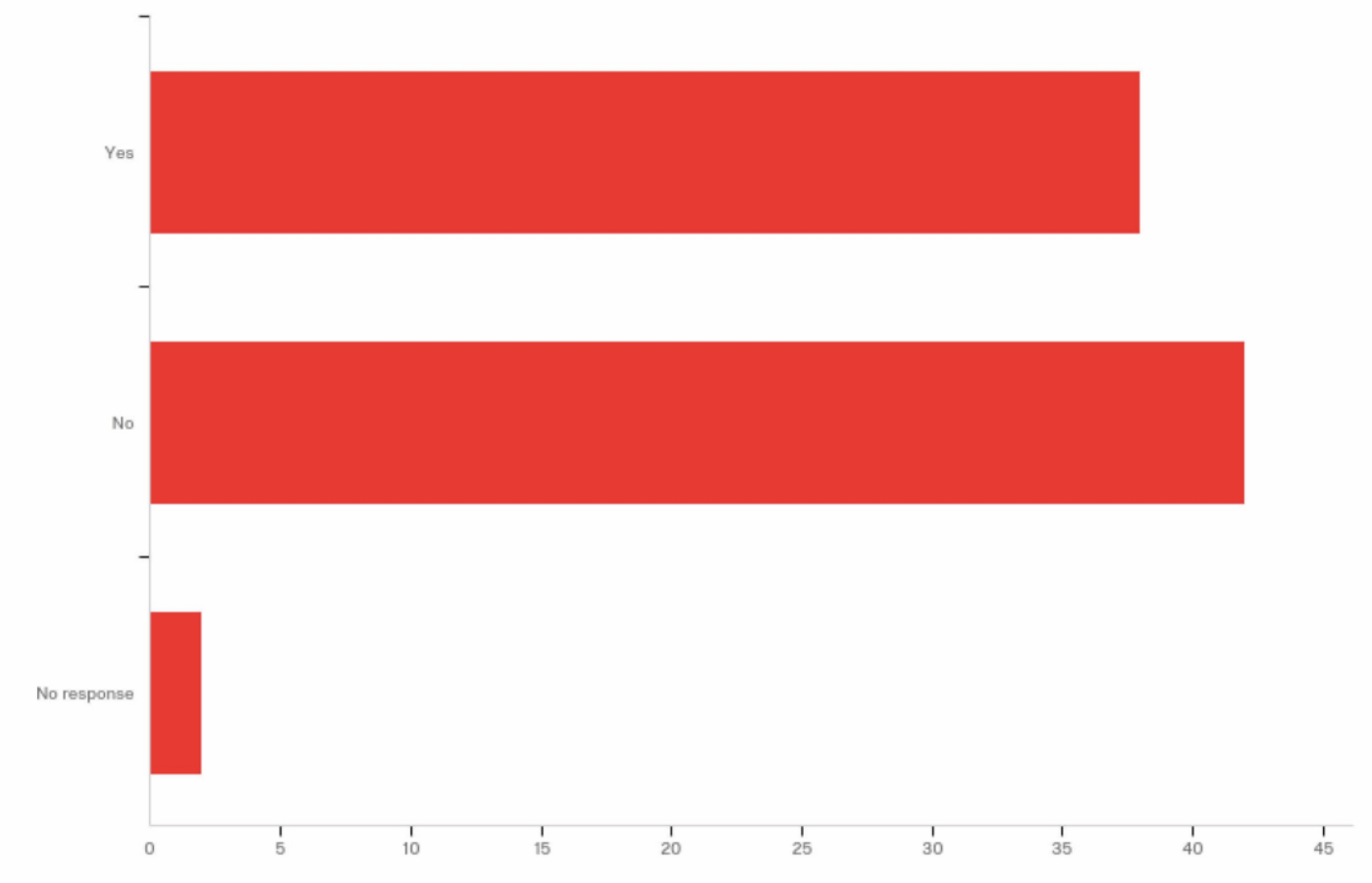


QID25 - How would you describe yourself?

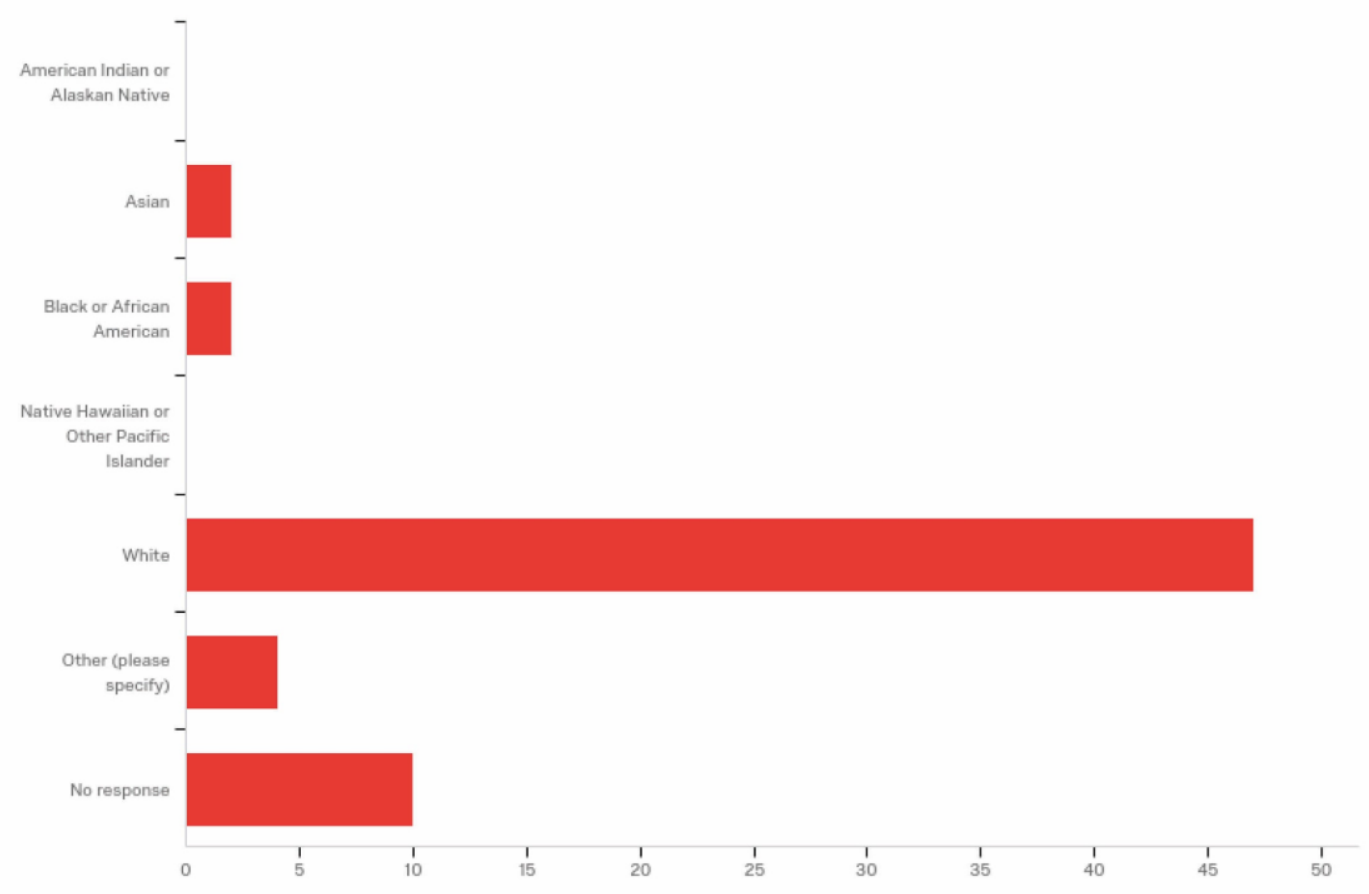

